\author{
RESEARCH ARTICLE \\ 10.1029/2019JB017587 \\ Key Points: \\ - From 1963 to 1973 , the U.S. \\ Geological Survey acquired 356 \\ marine heat flow measurements \\ from a drifting ice island in the \\ Arctic Ocean \\ - These never-before-published data \\ greatly expand the number of \\ marine heat flow measurements in \\ the high Arctic Ocean \\ - Heat flow averages $54.7 \pm 11.3$ \\ $\mathrm{mW} / \mathrm{m}^{2}$, with average values on \\ Alpha-Mendeleev Ridge and in \\ Canada Basin and elevated values in \\ Nautilus Basin
}

Correspondence to:

C. D. Ruppel,

cruppel@usgs.gov

Citation:

Ruppel, C. D., Lachenbruch, A. H., Hutchinson, D. R., Munroe, R. J., \& Mosher, D. C. (2019). Heat flow in the Western Arctic Ocean (Amerasian Basin). Journal of Geophysical Research: Solid Earth, 124, 7562-7587. https://doi. org/10.1029/2019JB017587

Received 23 FEB 2019 Accepted 6 JUL 2019 Accepted article online 10 JUL 2019 Published online 6 AUG 2019

(c)2019. American Geophysical Union. All Rights Reserved.

\section{Heat Flow in the Western Arctic Ocean (Amerasian Basin)}

\author{
C. D. Ruppel ${ }^{1}$ ID, A. H. Lachenbruch², D. R. Hutchinson' ${ }^{1}$ (D) R. J. Munroe' ${ }^{2}$ and D. C. Mosher $^{3}$ (iD \\ ${ }^{1}$ U.S. Geological Survey, Woods Hole, MA, USA, ${ }^{2}$ U.S. Geological Survey (retired), Menlo Park, CA, USA, ${ }^{3}$ Geological \\ Survey of Canada, Dartmouth, Nova Scotia, Canada
}

\begin{abstract}
From 1963 to 1973 the U.S. Geological Survey measured heat flow at 356 sites in the Amerasian Basin (Western Arctic Ocean) from a drifting ice island (T-3). The resulting measurements, which are unevenly distributed on Alpha-Mendeleev Ridge and in Canada and Nautilus Basins, greatly expand available heat flow data for the Arctic Ocean. Average T-3 heat flow is $\sim 54.7 \pm 11.3 \mathrm{~mW} / \mathrm{m}^{2}$, and Nautilus Basin is the only well-surveyed area ( $13 \%$ of data) with significantly higher average heat flow $\left(63.8 \mathrm{~mW} / \mathrm{m}^{2}\right)$. Heat flow and bathymetry are not correlated at a large scale, and turbiditic surficial sediments (Canada and Nautilus Basins) have higher heat flow than the sediments that blanket the Alpha-Mendeleev Ridge. Thermal gradients are mostly near-linear, implying that conductive heat transport dominates and that near-seafloor sediments are in thermal equilibrium with overlying bottom waters. Combining the heat flow data with modern seismic imagery suggests that some of the observed heat flow variability may be explained by local changes in lithology or the presence of basement faults that channel circulating seawater. A numerical model that incorporates thermal conductivity variations along a profile from Canada Basin (thick sediment on mostly oceanic crust) to Alpha Ridge (thin sediment over thick magmatic units associated with the High Arctic Large Igneous Province) predicts heat flow slightly lower than that observed on Alpha Ridge. This, along with other observations, implies that circulating fluids modulate conductive heat flow and contribute to high variability in the T-3 data set.
\end{abstract}

\section{Introduction}

From 1963 to 1973, A. Lachenbruch, V. Marshall, and technical staff at the U.S. Geological Survey (USGS) acquired hundreds of marine heat flow measurements in the Arctic Ocean from a drifting ice floe named Fletcher's Ice Island, which was also known as T-3. T-3 Ice Island was used for military and scientific purposes starting in the early 1950s (Crary et al., 1952) until it ran aground in 1960. After part of the island detached and refloated in February 1962, the Naval Arctic Research Laboratory and the Office of Naval Research administered T-3 (Lachenbruch et al., 2019) for 4,606 days until 1974 (Hall, 2010). USGS heat flow research and associated coring commenced in early 1963 and continued during periods of USGS occupation of T-3 until November 1973.

The T-3 heat flow measurements were the first to ever be acquired in the highest latitudes of the Arctic Ocean or from a floating ice island. More than 50 years after the study was initiated, the data set is still the most extensive ever collected at these latitudes and alone provides more heat flow measurements than are available on some U.S. marine margins even today. Only a few early measurements and data summaries have been published (e.g., Lachenbruch \& Marshall, 1966; Lachenbruch \& Marshall, 1969; Langseth et al., 1990), and most of the data are not accurately accounted for in global heat flow compilations (IHFC, 2012). A subset of the oldest T-3 data is included in the database and have station designators starting with "FL." However, at the time of this paper's publication, the data in the IHFC (2012) are incorrectly attributed to "Langseth and Marshall (1966)" instead of Lachenbruch and Marshall (1966).

In this paper, we reanalyze the original data set as documented in an unpublished USGS report (Lachenbruch et al., 2019). We interpret the legacy heat flow data within the context of contemporary perspectives on Arctic Ocean tectonics, crustal age, and sedimentation patterns using seismic data acquired mostly since 2000. An associated data release (Ruppel et al., 2019) links to the original postexpedition report (Lachenbruch et al., 2019) and provides more background on the modern analysis of the T-3 data along with T-3 1-hr navigation and gravity and magnetic data from 1962 to 1974. 


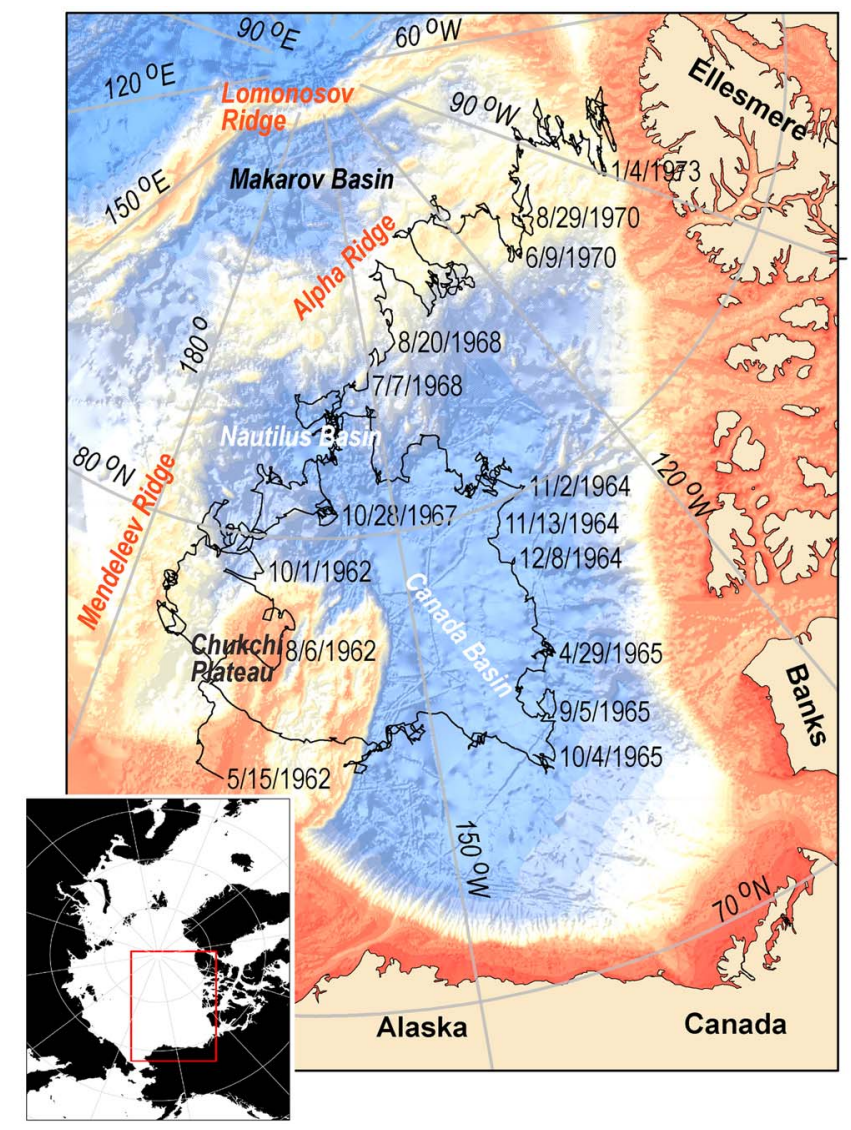

Figure 1. (inset) Location map for the Amerasian Basin area depicted in the larger map, shown in a polar projection. (main map) Drift path (black) for the T-3 (Fletcher's) ice island between May 1962 and August 1974, based on daily navigational fixes provided by J. K. Hall (personal communication, 2016) and available digitally in Ruppel et al. (2019). Base map depicts shallow bathymetry in orange and deep bathymetry in blue and is taken from Boggild et al. (2018).

\section{Setting}

During a decade of USGS heat flow measurements, T-3 Ice Island drifted in the Arctic Ocean between $75^{\circ} \mathrm{N}$ and $86^{\circ} \mathrm{N}$ latitude and $77^{\circ} \mathrm{W}$ and $176^{\circ} \mathrm{W}$ longitude, carried first by the Beaufort Gyre and then pushed by the ice pack along Alpha Ridge toward Ellesmere Island. T3 covered a total track line of more than $21,000 \mathrm{~km}$ during the period of the measurements, all contained within an area measuring $\sim 1,900 \mathrm{~km}$ by 1,100 km (Figure 1). Relatively little was known about the evolution of the Arctic Ocean basin at the time of the data acquisition, and even today controversy continues about the tectonic evolution of major features (e.g., Amato et al., 2017; Nikishin et al., 2017; Shephard et al., 2013).

The key physiographic features of the Western Arctic Ocean, which is formally known as the Amerasian Basin (both terms are used in this study), are Canada Basin and associated Nautilus Basin, Alpha-Mendeleev Ridge (AMR), and Chukchi Plateau/Northwind Ridge and intervening Northwind Basin. Jakobsson et al. (2003) identify several additional physiographic features (e.g., Nautilus Submarine Highlands, Chukchi Spur) in the study area, but these are not considered as separate locations here. Jakobsson et al. (2003) also combine several physiographic provinces in their analysis, while we discuss the Alpha and Mendeleev Ridges separately and recognize the southern part of Nautilus Basin as Mendeleev Plain. The origin and structure of Arctic Ocean physiographic features have significant implications for interpretation of marine heat flow data, but the section below provides only an overview of key features.

\subsection{Canada Basin and Nautilus Basin}

Canada Basin is the dominant physiographic feature of the Western Arctic Ocean, comprising an estimated $7.4 \times 10^{5} \mathrm{~km}^{2}$ (Jakobsson et al., 2003). Progressing counterclockwise, Canada Basin is bound by the U.S. and Canadian Beaufort margins, the Canadian Arctic Islands, Alpha Ridge, and Northwind Ridge. As defined by Jakobsson et al. (2003), Nautilus Basin occupies an additional $1.24 \times 10^{5} \mathrm{~km}^{2}$ in a lobe north and west of Canada Basin and south of Alpha Ridge. Based on physiography, Jakobsson et al. (2003) include in Nautilus Basin an area typically known as Mendeleev Plain, which comprises the terraces and rugged hills that descend from Chukchi Plateau and Mendeleev Ridge into the southern part of Nautilus Basin.

Much of Canada Basin is remarkably flat at water depths of $\sim 3,850 \mathrm{~m}$, while water depths in the parts of Nautilus Basin that are contiguous with Canada Basin are slightly shallower $(\sim 3,820 \mathrm{~m})$. Mendeleev Plain terraces and hills in the southern and southeastern parts of Nautilus Basin have water depths between 3,600 and 2,700 m. At the time of the T-3 data set acquisition, Nautilus Basin was not typically distinguished from Canada Basin (e.g., Dietz \& Shumway, 1961) and is often referred to as "northwest Canada Basin" in the original data records (Lachenbruch et al., 2019).

The central part of Canada Basin overlies oceanic crust that was created at an extinct spreading ridge oriented north-south through the main part of the basin (Chian et al., 2016; Mosher et al., 2012). Thinned continental crust flanks the oceanic crust on both the west and east. The northern part of Canada Basin and the entire Nautilus Basin, which coincide with the High Arctic Magnetic High (HAMH as shown in Figure 2; Oakey \& Saltus, 2016), are likely underlain by a combination of highly stretched continental and volcanic basement (Chian et al., 2016). Sediment thicknesses in Canada Basin range from greater than 12 $\mathrm{km}$ in the south near the U.S. and Canadian Beaufort margins to almost zero in parts of Nautilus Basin and near Nautilus and Sever Spurs (Mosher \& Hutchinson, 2019) on the north (Figure 2). Mosher and Hutchinson (2019) and Boggild et al. (2018) provide interpretations of the sedimentary regime in these locations. The eastern part of Canada Basin hosts nonturbiditic sediment drift deposits. Turbidites dominate 


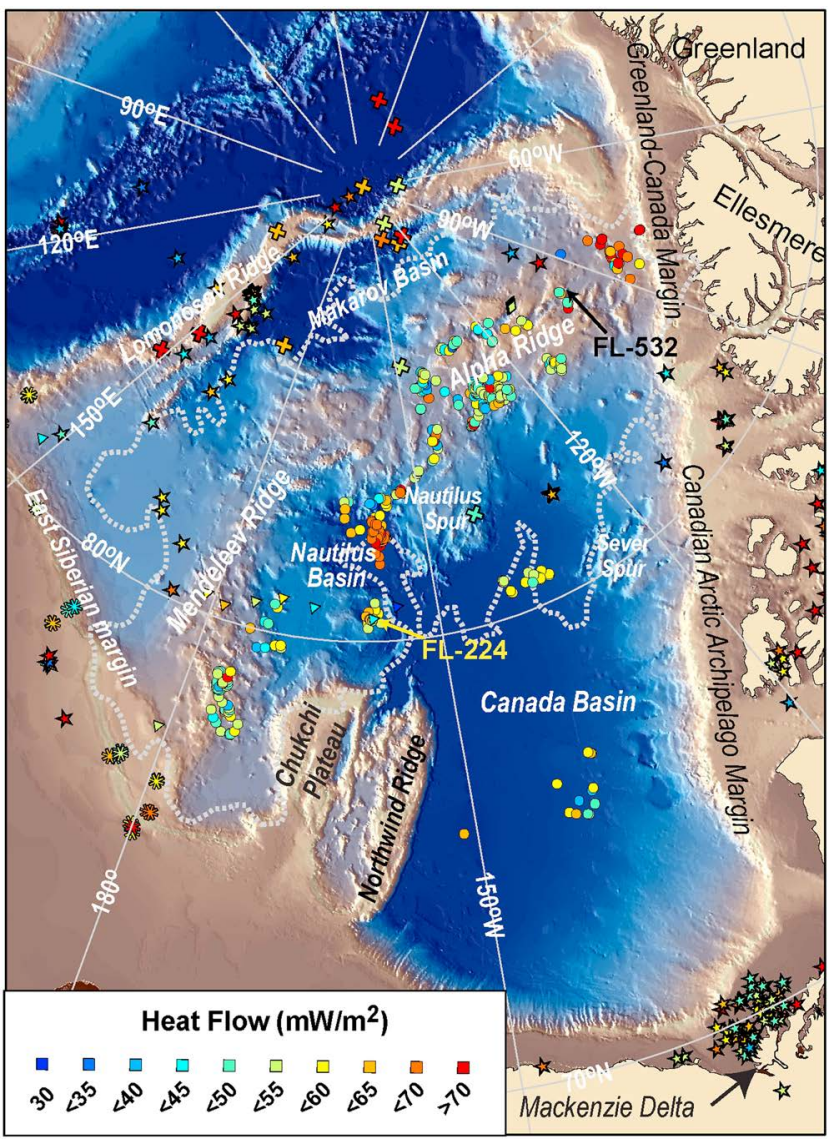

Figure 2. Compiled heat flow measurements for the Amerasian Basin and part of the Eurasian basin, color coded by measured heat flow, with the outline of the HAMH shown by the dashed white curve. T-3 measurements are depicted as circles, CESAR ice island heat flow (Taylor et al., 1986) as diamonds, data collected roughly along $81^{\circ} \mathrm{N}$ (Jokat, 2009) as triangles, East Siberian margin data (O'Regan et al., 2016) as asterisks, recent Oden heat flow data and some additional previously unpublished data (Shephard et al., 2018) as crosses, and other historic heat flow measurements documented in the Global Heat Flow database (IHFC, 2012) as stars. Not shown is a recent survey of the Lomonosov Ridge by Xiao et al. (2013) nor Eurasian basin data from Urlaub et al. (2009). T-3 labeled point FL-224 is referred to in section 5.1. FL-532 was correctly digitized but does not plot on the known navigational track of T-3. MP refers to the Mendeleev Plain. sedimentary sequences in the western part of Canada Basin and extend into the deep part of eastern Nautilus Basin. The shallower western and southern parts of Nautilus Basin (Mendeleev Plain) are in a lower energy setting and draped by hemipelagic sediment.

\subsection{AMR}

Most of the heat flow data were acquired as T-3 Ice Island drifted above Alpha Ridge and the southeastern part of Mendeleev Ridge. AMR forms a bathymetric high standing up to $\sim 2,600 \mathrm{~m}$ above the Canada Basin and $\sim 3,000 \mathrm{~m}$ shallower than Makarov Basin to the west. Early in the geophysical exploration of the Arctic Ocean, AMR, which stretches $\sim 1,700$ $\mathrm{km}$ from the Siberian upper continental slope to the continental margin off Ellesmere Island, was interpreted as an extinct spreading ridge based in part on magnetic data collected on T-3 (Hall, 1970; see also Ruppel et al. (2019) for T-3 magnetic data). The original analysis of the USGS heat flow data (Lachenbruch et al., 2019) searched for symmetry in the measured values as a function of distance from the shallowest part of AMR, an unsuccessful test of the spreading ridge hypothesis.

Starting in the late 1970s, the spreading ridge interpretation for AMR was abandoned (e.g., De Laurier, 1978), and researchers increasingly recognized the role of effusive volcanism or even a hot spot in the formation of AMR (Forsyth et al., 1986; Lawver \& Müller, 1994; Vogt et al., 1979). It is now widely accepted that AMR is part of the High Arctic Large Igneous Province (HALIP), where an estimated $2 \times 10^{7} \mathrm{~km}^{3}$ of igneous rock (Oakey \& Saltus, 2016) was emplaced during several pulses between $\sim 121$ to 112 and 84 to $73 \mathrm{Ma}$ (Dockman et al., 2018; Jokat et al., 2013; Mukasa et al., 2015). Dockman et al. (2018) concluded that only the oldest phase of volcanism associated with AMR may have involved direct interaction with a hot spot. Researchers have identified HALIP components that are a continuation of AMR-related magma emplacement into the Sverdrup Basin and Canadian archipelago (Dockman et al., 2018; Estrada et al., 2016; Saumur et al., 2016) and onto Greenland, Franz Josef Land, and Svalbard (Corfu et al., 2013; Nejbert et al., 2011; Tegner et al., 2011).

The evolution of AMR is intertwined with the presence of continental crust in this part of the Arctic Ocean basin. The emerging consensus is that the HALIP, of which AMR is part, was formed from a mantle plume source interacting with continental crust (e.g., Jackson et al., 2018). Kashubin et al. (2018) infer a 20-km-thick sequence of felsic (continental?) lower crust, underplated magmatic material, and upper mantle eclogites beneath Mendeleev Ridge based on seismic data. Seismic imaging and potential field data imply that the ridge complex is underlain by thickened crust, which is interpreted by Lebedeva-Ivanova et al. (2006) as representing remnant continental material and by Oakey and Saltus (2016) as either oceanic crust or highly attenuated continental crust intruded by ultramafic rocks. Kusznir and Gaina (2011) and Jackson et al. (2018) rely on gravity and modern seismic data to also conclude that continental material may have been involved in AMR's evolution.

From magnetic anomaly data and observations of radiating dikes, Døssing et al. (2013) proposed that a highamplitude, circular magnetic anomaly on Alpha Ridge may represent a supervolcano from which much of the HALIP magma erupted. Basalt samples from HALIP, including from Alpha and Mendeleev Ridges, are largely alkalic to subalkalic, as is common in some continental flood basalts. Other geochemical results show that HALIP was clearly not formed by volcanism at an island arc or extrusion of mid-ocean ridge basalts (MORB) at a mature spreading center (e.g., Jokat et al., 2013; Morozov et al., 2013; Mukasa et al., 2015; Petrov et al., 2016; Sergeev et al., 2013; Van Wagoner et al., 1986). Additionally, clasts within HALIP 
basalt samples indicate enrichment in light rare earth elements and slight enrichment in heavy rare earth elements compared with normal MORB (N-MORB) or Icelandic type-enhanced MORB (E-MORB). This suggests probable contamination of the magma by preexisting crustal material, possibly of continental origin (Jokat et al., 2013; unpublished manuscript of Mukasa, S. B., Andronikov, A., Brumley, K., Mayer, L. A., and Armstrong, A., "Basalts from the Chukchi Borderland: ${ }^{40} \mathrm{Ar} /{ }^{39} \mathrm{Ar}$ ages and geochemistry of submarine intraplate lavas recovered from the western Arctic Ocean," in revision for Journal of Geophysical Research, 2019; M. C. Williamson, personal communications, 2019). Funck et al. (2011), Døssing et al. (2013), Mukasa et al. (2015), Kusznir and Gaina (2011), Oakey and Saltus (2016), and Jackson et al. (2018) use seismic, gravity, and magnetic data from AMR to make an analogy between this feature and the Kerguelen LIP, which is known to have developed in association with continental crustal material.

The basement of Mendeleev Ridge is disrupted by normal faulting in some places and is relatively intact, but not smooth, in other locations. The ridge is blanketed by hemipelagic sediments several hundred meters thick, with over a kilometer of sediment in some grabens (Bruvoll et al., 2010). Alpha Ridge has a similar basement structure to Mendeleev Ridge and sediment thickness ranging from 0 to 1,200 m (Bruvoll et al., 2012; Evangelatos et al., 2017; Jackson et al., 1986; Jokat, 2003; Jokat et al., 2013).

\subsection{Chukchi Plateau and Northwind Ridge}

The T-3 data set includes no measurements on Chukchi Plateau or Northwind Ridge, but these features are briefly described here due to their geographic prominence in the Western Arctic Ocean. Chukchi Plateau and Spur and Northwind Ridge together form Chukchi Borderland, which rises from the $\sim 3,800$-m-deep Canada Basin to depths as shallow as $\sim 350 \mathrm{~m}$ (Chukchi) to $\sim 550 \mathrm{~m}$ (Northwind). Chukchi Borderland and Northwind Basin and Ridge occupy $\sim 1.95 \times 10^{6} \mathrm{~km}^{2}$ of Amerasian Basin and lie on continental crust that is thicker and more intact (less attenuated) than that beneath the adjacent parts of Nautilus and Canada basins (Kashubin et al., 2018). Only the northernmost part of Chukchi Plateau lies within the HAMH (Oakey \& Saltus, 2016). Thus, the continental crust that underlies most of Chukchi Borderland is likely not magmatically altered to the extent of that beneath Nautilus Basin or southern Mendeleev Ridge. Sediments on Northwind Ridge and Chukchi Plateau are thin (Ilhan \& Coakley, 2018; Shimeld et al., 2016), and seafloor features show evidence of having been glacially eroded (Polyak et al., 2017).

\section{Methods}

The T-3 heat flow data were usually acquired at intervals of one to seven days whenever USGS scientists were stationed on the drifting ice island. Intervals were longer between measurements when attempted heat flow casts were unsuccessful (indicated by nonsequential cast numbers; Ruppel et al., 2019), when weather conditions were too difficult, when the island was drifting too rapidly, or when USGS personnel were not present on the island. Prior to September 1965, continuous USGS occupation was confined to July through September, with supplementary multiweek visits made during the winter. USGS teams spent more time on T-3 after that because the island began to drift rapidly (Lachenbruch et al., 2019). After 1965, data were at some point acquired in every season during the next eight years of sporadic USGS occupation of the ice camp. Over the course of the T-3 heat flow surveys, more data were collected in winter (29.5\% in January through March) than in summer (20\% in June through August).

The dates of the heat flow measurements are not provided in the original database (Lachenbruch et al., 2019). Because the heat flow probe simultaneously acquired a piston core during many deployments, dates were assigned in Ruppel et al. (2019) by first merging the known dates of T-3 piston cores (University of Wisconsin, 2015) with the heat flow database and then determining the dates of most of the remaining stations by comparing the T-3 navigational record (J. K. Hall, personal communications, 2016; data in Ruppel et al. (2019)) to the recorded position of the heat flow measurements. Metadata in Ruppel et al. (2019) describe the problems with this approach, which is the only one possible given the lack of original information about heat flow measurement dates.

The longest gaps between successful heat flow measurements were 299 and $~ 229$ days in 1965-1966 and 1972-1973, respectively. There were additional gaps of more than 120 days in 1964, 1965, and 1973 and twice in 1966 and in 1971. As noted above, the time gaps led to no heat flow data being acquired as T-3 drifted 
across Northwind Ridge and Chukchi Plateau in 1966. Nor were data acquired in large parts of Canada Basin during T-3's transit in 1964 and 1965. J. K. Hall (personal communications, November 2018) noted that heat flow data and cores were also not collected in spring or summer 1967 because the USGS equipment malfunctioned on the first measurement attempt after the researchers were left on the ice without transportation or resupply for the remainder of the summer field season.

Until an unknown time in 1967, T-3 navigation relied on a theodolite to measure the island's position relative to stars in the winter and the Sun in the summer and on a chronometer that was frequently verified with radio time checks (Hunkins \& Tiemann, 1977). In terms of hardware, this navigational equipment represented only slight improvement over that available to Arctic Ocean explorers in the nineteenth and early twentieth centuries, when radio time checks were of course not available. Hunkins and Tiemann (1977) estimate a positional error of up to $1 \mathrm{~km}$ during the summer and $0.5 \mathrm{~km}$ in the winter for the period when celestial navigation was used. Starting in 1967, polar-orbiting satellites (Transit or Navy Navigation Satellite System) provided frequent positional fixes, and Hunkins and Tiemann (1977) estimate that positions were thereafter known within $250 \mathrm{~m}$. No information is available to determine whether the positional information in the heat flow database indicates the position at the beginning or end of a measurement, which could take several hours when water depths were large. The precise location of the measurement on the seafloor might also be displaced from the surface equipment, a persistent problem for modern heat flow measurements made from ships. One-hour interpolated navigational data for T-3 Ice Island from 1962 to 1974 are available in Ruppel et al. (2019). More background about T-3 Ice Island navigation is given in Hall (2010).

At each heat flow station, sediment thermal gradients were measured using four (usually) to five (later parts of the T-3 data set) outrigged thermistors separated by $\sim 1 \mathrm{~m}$ and attached to a core barrel (Lachenbruch et al., 2019). An additional thermistor near the top of the core barrel measured bottom water temperature (BWT), although these values are not separately reported in the tabular summary in Lachenbruch et al. (2019). Nominal thermistor precision was on the order of $10^{-3}{ }^{\circ} \mathrm{C}$. Core barrel lengths ranged from $3.05 \mathrm{~m}$ for earlier measurements to $3.66 \mathrm{~m}$ in later years, meaning that the later measurements could only have had five thermistors separated by $\sim 0.91 \mathrm{~m}$ instead of the $\sim 1 \mathrm{~m}$ reported separation for the earlier fourthermistor probes.

To make a thermal measurement and simultaneously acquire a sediment core, the core barrel and attached instrumentation package were lowered through a permanent hole in the ice using a winch and tripod system (Lachenbruch et al., 2019). On retrieval, the corer was swung clear of the access hole using a sling system similar to that used for piston corer management on some modern oceanographic vessels. A structure ("Hydrohut") sheltered the access hole (moonpool) to maintain the integrity of the ice around the opening and to allow the operator to work regardless of weather conditions. The USGS facility was located near the Lamont Geological Observatory (renamed Lamont-Doherty Geological Observatory in 1969) hydrohut on a part of T-3 called Colby Bay (Figure 3).

Heat flow probes developed after the T-3 measurements commenced could often measure thermal conductivity $(K)$ in situ in marine sediments (Sclater et al., 1969) by tracking the decay of a controlled heat pulse (Hyndman et al., 1979; Lister, 1979). Such instrumentation was not deployed for the T-3 experiment. Instead, sediments recovered during heat flow operations were preserved for benchtop needle probe thermal conductivity measurements (Von Herzen \& Maxwell, 1959) on T-3 or in the USGS laboratory at Menlo Park (Lachenbruch \& Marshall, 1966). In normal practice, such thermal conductivity data are adjusted to in situ (seafloor) values using the methods outlined by Ratcliffe (1960) and later updated in Hyndman et al. (1979) and Pribnow et al. (2000) to account for laboratory conditions that are at higher temperature (resulting in higher measured $K$ ) and substantially lower pressure (resulting in lower $K$ ) than at the seafloor. Based on Lachenbruch et al. (2019), we infer that the corrections were applied to the original thermal conductivity data before interval averages (Table 1) were computed. Even if the corrections were not fully applied to the original data, we calculate that the magnitude of the net corrections is so small for sediments extracted from cold and deep waters that retention of the values reported by Lachenbruch et al. (2019) is merited.

The physical records for each heat flow cast were made on 35-mm film or chart recorders. We attempted to locate these physical records or the associated derived plots of the original data at USGS facilities, but were unsuccessful. To update the legacy USGS T-3 heat flow data set for modern analysis, the summary tables in the original unpublished report (Lachenbruch et al., 2019) were first digitized using a combination of 


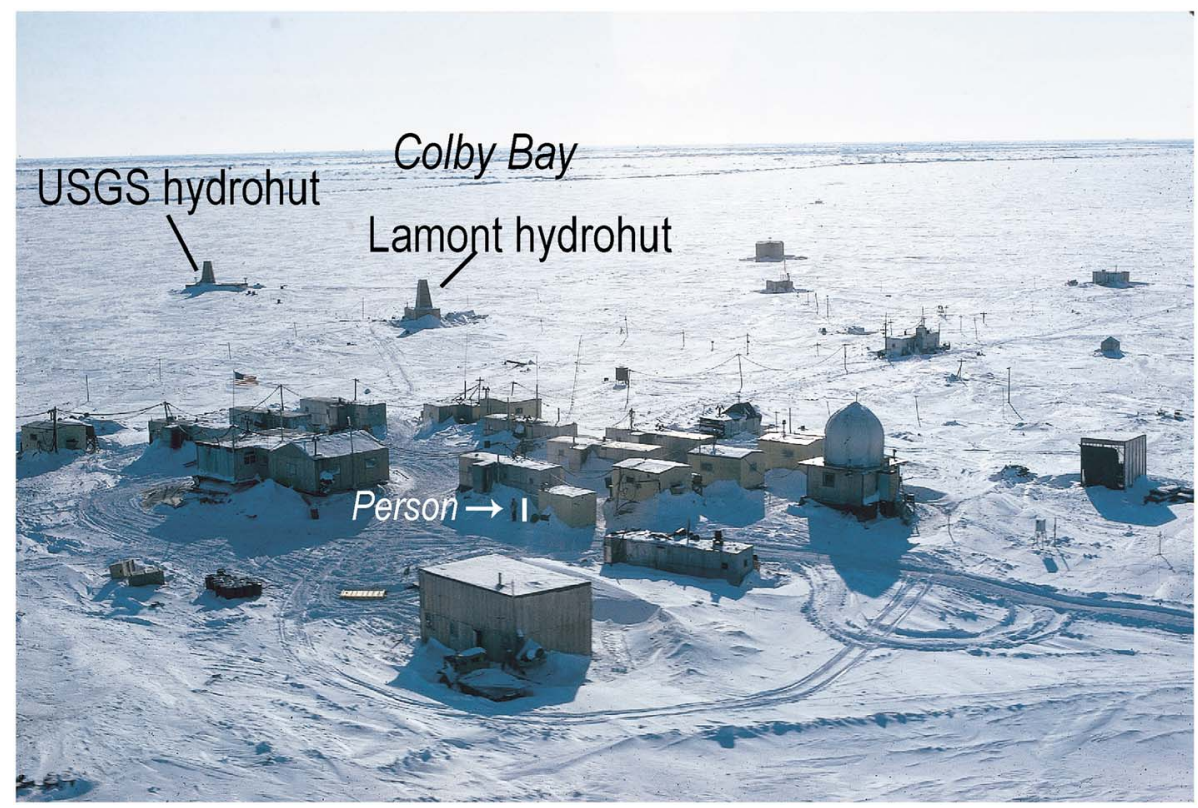

Figure 3. Photograph of T-3 Ice Island science buildings and living quarters taken by J. K. Hall in spring 1967 from a Huey helicopter used by researchers to visit other parts of the island to acquire gravity measurements. The USGS hydrohut contained the coring and heat flow equipment that was deployed through a moonpool in the ice and lowered to the seafloor by a winch system. Person in center next to white bar for scale. Photo courtesy of J. K. Hall (personal communication, November 2018).

manual data entry and optical character recognition. The resulting digital tables were extensively verified against the original report to ensure accuracy. The data files and more information about the digitization process can be found in Ruppel et al. (2019). The first 20 measurements from the heat flow database of Lachenbruch et al. (2019), along with information integrated into the data files by Ruppel et al. (2019) during preparation of this study, are shown in Table 1.

USGS researchers attempted a total of 584 T-3 heat flow casts, of which 356 yielded heat flow results. Nineteen of these measurements were previously published by Lachenbruch and Marshall (1966) in summary form. More data summaries, although not the original data, were given in the review of Langseth et al. (1990). As noted earlier, some early data, but with incorrect attribution to the source of the data (as of mid-2019), are included in various versions of the IHFC (2012).

The data tables in Lachenbruch et al. (2019) do not provide raw equilibrium temperatures $\left(T_{e q}\right)$ measured by the thermistors, as is common practice today. $T_{e q}$ would have been obtained from graphical records showing the frictional heating pulse as the corer entered the seafloor and the subsequent conductive re-equilibration interval. These original records also could not be found at the USGS in recent years. Summary tables for $T_{e q}$ and BWT are also not available, nor are records detailing exact thermistor positions and functioning or seafloor-penetrating thermistors for each cast. The analysis here therefore relies exclusively on alreadycalculated thermal gradients reported by Lachenbruch et al. (2019) instead of reanalysis of equilibration records, original log sheets, and related raw data. Despite the fact that many of the analyses and calculations reported in Lachenbruch et al. (2019) were done by hand or with rudimentary computers, the recalculations done for the study showed the results to be robust in nearly all cases. Thus, we have confidence in using tabular, already-reduced data recorded in Lachenbruch et al. (2019) as a starting point for this study.

The data in Lachenbruch et al. (2019) provide thermal gradients in units of $10^{-3}{ }^{\circ} \mathrm{C} / \mathrm{m}$ between adjacent bottom-penetrating thermistors (thermistor 1 was the deepest). When thermistors malfunctioned, the tabulated gradients are calculated between the adjacent functioning thermistors (Table 1). Based on the explanations given in Lachenbruch and Marshall (1966), it is believed that the thermal gradients between bottompenetrating thermistors (as reported by Lachenbruch et al., 2019) were calculated by first subtracting the recorded BWT value from each subseafloor equilibrium temperature determination, yielding a reduced temperature value measured relative to BWT temperatures at each subseafloor depth. 


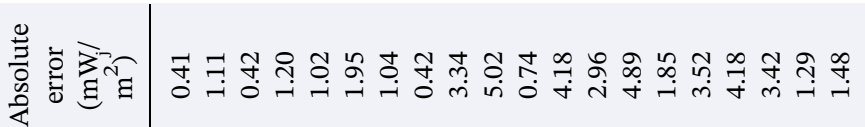

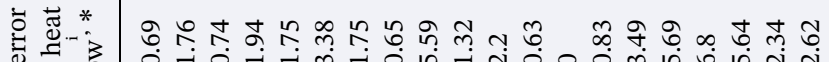

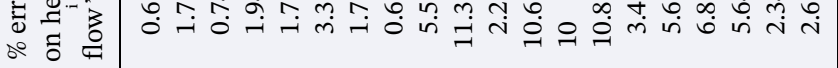

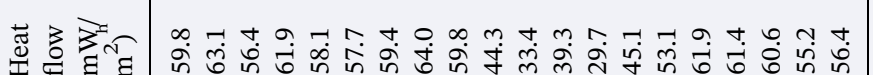

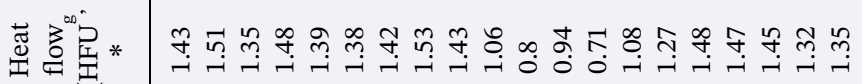

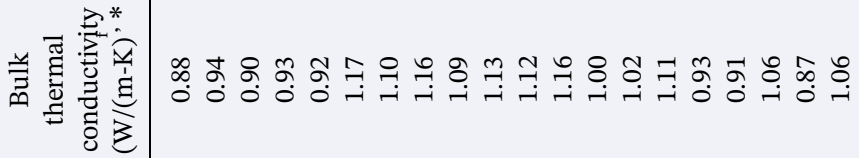

๙ิे

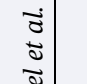

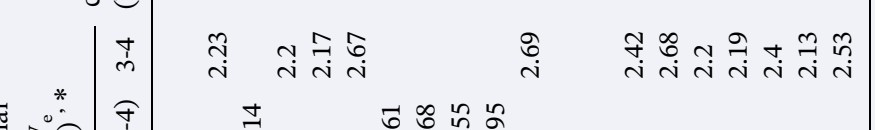

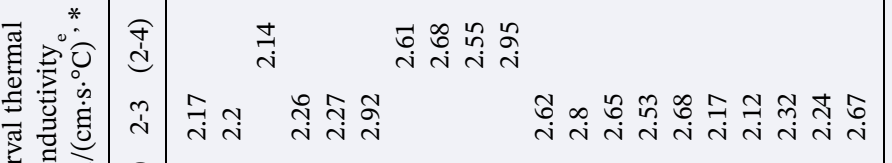

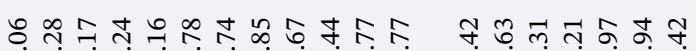

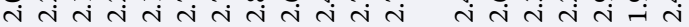

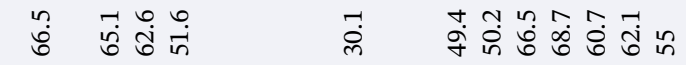

苞

ลิ่

in

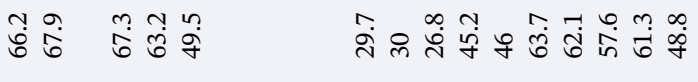

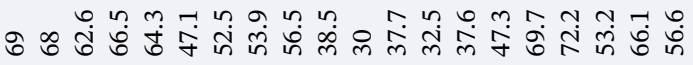

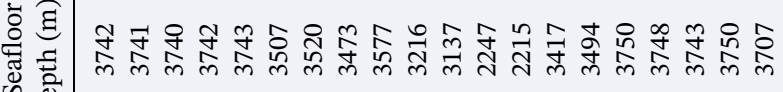

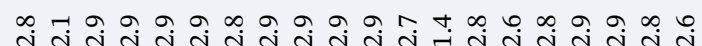

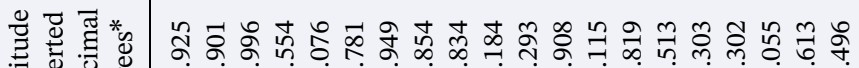

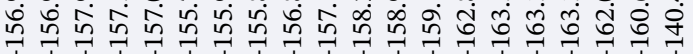

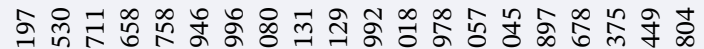

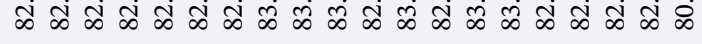

గి గి

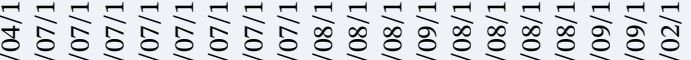

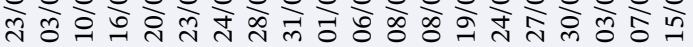

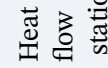
*i.

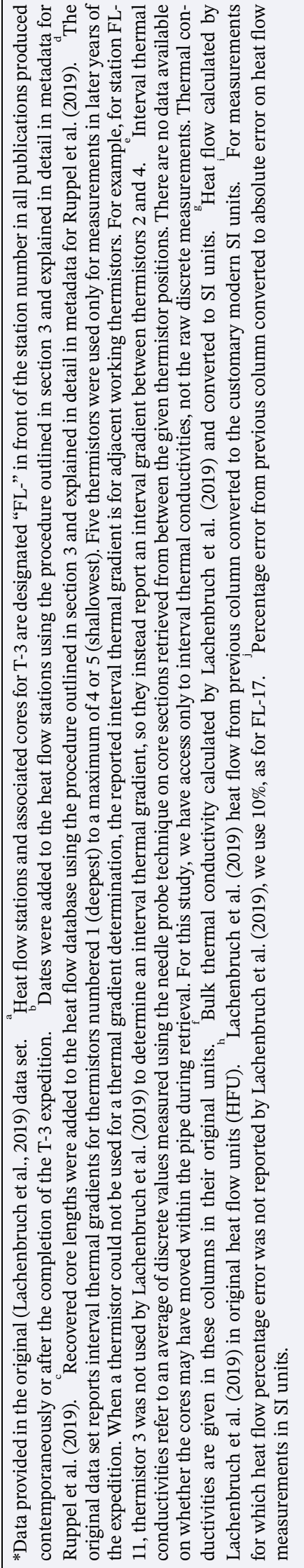


Thermal conductivities $K$ were reported by Lachenbruch et al. (2019) in units of mcal cm ${ }^{-1} \mathrm{~s}^{-1}{ }^{\circ} \mathrm{C}^{-1}$ based on needle probe (Von Herzen \& Maxwell, 1959) benchtop analysis of the cored sediments at positions corresponding to the sections between the thermistors. Lachenbruch et al. (2019) report that sediment cores were recovered from 546 of the casts (93\%), with the total length of recovered core reported as $1.486 \mathrm{~km}$. This yields an average of $2.72 \mathrm{~m}$ per core, which is shorter than the length of the corer, indicating that the corer often did not fully penetrate the seafloor or that the sediments compressed and that material within the corer could sometimes have shifted during recovery. The University of Wisconsin received over 300 of the cores (Clark, 1971; Clark et al., 1980), most of which are documented in the NCEI database (University of Wisconsin, 2015). For this study, we also had access to an additional T-3 core database developed by D. Darby (personal communications, 2016) to support studies of sediment provenance in the Amerasian Basin (Darby et al., 1989). We attempted to compare the lengths of recovered cores with the thermistor intervals where thermal gradients were reported for each heat flow site (Lachenbruch et al., 2019) to determine if the core length could be used as a proxy for probe penetration depth. In light of substantial inconsistencies (e.g., gradients being reported for the shallower thermistor intervals despite only a short core being recovered), this strategy for constraining heat flow probe penetration depth was abandoned.

Heat flow was originally calculated by Lachenbruch et al. (2019) in heat flow units (HFU; $10^{-2} \mathrm{cal} \mathrm{m}^{-1} \mathrm{~s}^{-1}$ ) by multiplying the interval thermal gradient by the corresponding interval thermal conductivity and then averaging the resulting value over the number of successful thermal gradient measurements for the cast. In the modern database, values originally given in HFU have been converted to customary modern heat flow units based on SI $\left(\mathrm{mW} / \mathrm{m}^{2}\right)$, and the averaging has been verified with spreadsheet functions. The original database gives measurement errors as a percentage of the calculated heat flow, labeled "average percentage deviation." We retain the percentage error on the converted heat flow values and calculate an absolute uncertainty in $\mathrm{mW} / \mathrm{m}^{2}$. For 73 of the successful heat flow casts $(20.5 \%)$, uncertainties were not reported, and we assign a conservative value of $\pm 10 \%$ (Table 1 ).

In the 1960s and 1970s, researchers used early gamma ray spectrometric methods to determine the concentration of heat-producing uranium, thorium, and potassium (U, Th, K) in recovered sediment samples (e.g., Bunker \& Bush, 1966, 1967). For the T-3 heat flow data set, C. Bunker at the USGS Denver laboratory measured radiogenic heat content for sediment samples from 26 of the recovered cores, mostly from Nautilus Basin and the southern Mendeleev Ridge. The results were reported by Lachenbruch et al. (2019) in heat mass units ( $\mu \mathrm{cal} \mathrm{g} \mathrm{gr}^{-1}$ ), as was common in the late 1960s. These units must be converted to SI units and multiplied by density to be comparable to modern heat production volumetric measurements in units of $\mathrm{W} / \mathrm{m}^{3}$. Given the uncertainty in the choice of appropriate densities to adopt for this conversion, most of the discussion of radiogenic heating in this paper uses the SI version of heat production mass unit (W/ $\mathrm{kg}$ ), here denoted as $A_{m u}$. Heat flow measurements were not always obtained at the locations of the cores used for the radiogenic heat determinations, which are fully documented in Ruppel et al. (2019).

\section{Results}

\subsection{Heat Flow}

Heat flow values reported for the entire data set are shown graphically in Figure 2, and average heat flow is $\sim 54.7 \pm 11.3 \mathrm{~mW} / \mathrm{m}^{2}$. The original reported heat flow calculations use the average of the interval thermal gradients multiplied by the average discrete thermal conductivities measured on cores from each site (Lachenbruch et al., 2019). The discrete (individual) needle probe thermal conductivity values are no longer available. If heat flow is instead calculated by multiplying the average interval thermal gradients by the average reported interval thermal conductivities for each site, the average value for the data set remains the same and the absolute uncertainly increases by $\sim 5 \%$.

The differences between the original and the recalculated heat flow determinations for individual measurements are $2 \%$ or smaller for $93.5 \%$ of the sites. At the remaining locations, the differences between the original and recalculated heat flow might be attributed to one or more factors, including (1) the use of interval thermal conductivity values, instead of the original measured discrete values, for the new calculation; (2) the reliance on averages of the thermal gradients in the new calculation, even when these gradients varied by more than $20 \mathrm{mK} / \mathrm{m}$ between intervals; or (3) rarely, tabular data that were illegible in the original 
Table 2

Heat Flow Statistics by Physiographic Province for the T-3 Data Set

\begin{tabular}{|c|c|c|}
\hline Physiographic province & $\begin{array}{l}\text { Number of } \\
\text { measurements }\end{array}$ & $\begin{array}{l}\text { Heat flow } \\
\left(\mathrm{mW} / \mathrm{m}^{2}\right)\end{array}$ \\
\hline Alpha Ridge & 209 & $53.3 \pm 12.2$ \\
\hline Mendeleev Ridge & 60 & $50.0 \pm 6.8$ \\
\hline Canada Basin & 30 & $54.5 \pm 5.6$ \\
\hline $\begin{array}{l}\text { Nautilus Basin (NB), } \\
\quad \text { including Mendeleev Plain }\end{array}$ & 49 & $63.8 \pm 6.1$ \\
\hline $\begin{array}{l}\text { Greenland-Canada } \\
\text { margin/slope }\end{array}$ & 8 & $71.3 \pm 9.3$ \\
\hline All data & 356 & $54.7 \pm 11.3$ \\
\hline
\end{tabular}

(Lachenbruch et al., 2019) and therefore could not be properly digitized (see original data component within Ruppel et al. (2019)).

Table 2 reports the average heat flow values determined within the boundaries of the Arctic Ocean physiographic provinces defined by Jakobsson et al. (2003), but with Alpha Ridge and Mendeleev Ridge treated as separate provinces and a few stations right at the boundaries of provinces attributed to the province itself. Note that the heat flow measurements are not evenly distributed in space, meaning that the averages for the provinces can be skewed by clusters of measurements taken close together. Average heat flow on AMR as a whole and in Canada Basin is almost indistinguishable from the average for the whole data set, while Nautilus Basin has heat flow 17\% higher than the data set average, mostly due to data from the northern part (not from the southern Mendeleev Plain). Although not a focus of this study, the few measurements on the Greenland margin and slope yield notably higher heat flow than other areas sampled during the T-3 expedition. Table 2 also demonstrates far larger heat flow variability within Alpha Ridge than in other areas, and this variability drives most of the relatively large uncertainty ascribed to the average heat flow for the whole study.

A.

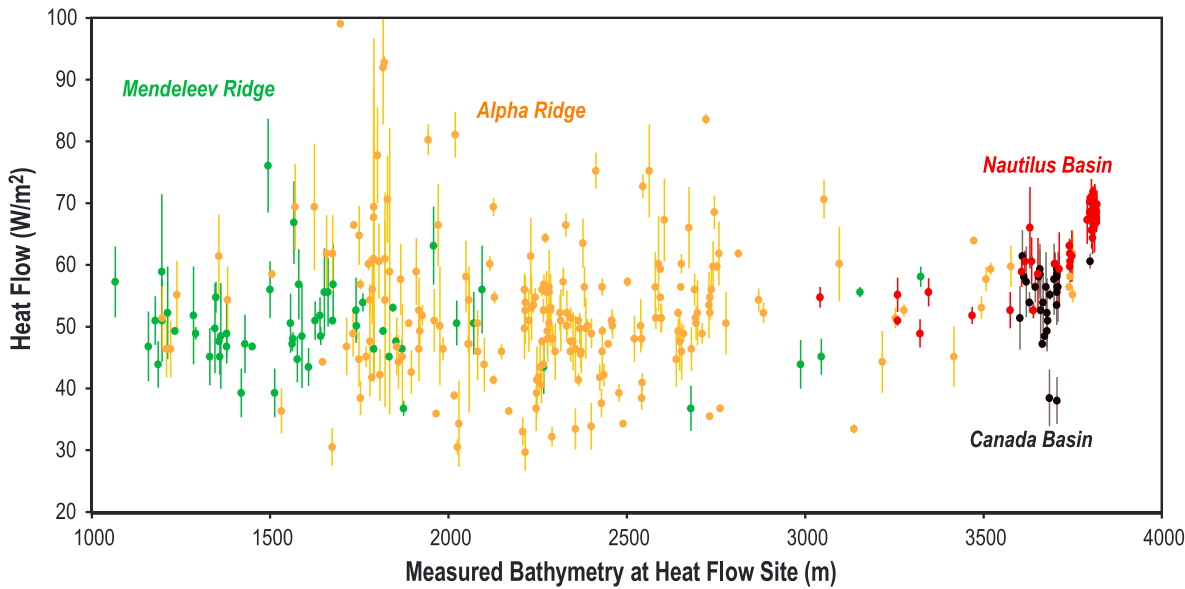

B.

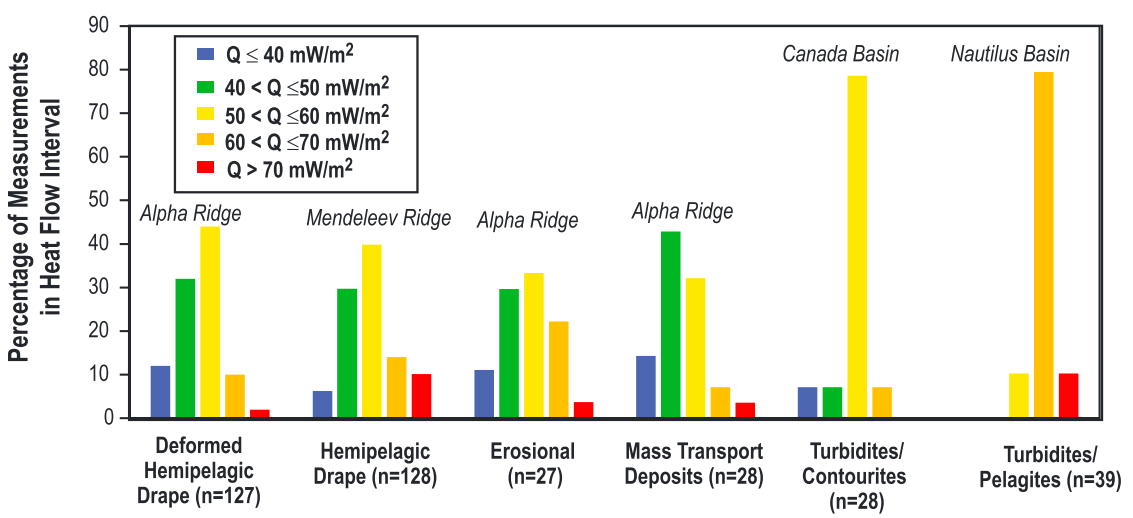

Figure 4. (a) T-3 heat flow measurements and calculated uncertainty plotted with bathymetry recorded in the original data set (Lachenbruch et al., 2019) for the four major physiographic provinces represented in the data set. The few data points for the Greenland-Canada margin are omitted, as is one measurement of $119.6 \mathrm{~mW} / \mathrm{m}^{2}$ (FL-389) from Alpha Ridge. Measurements from the submarine highlands province (Jakobsson et al., 2003) of Nautilus Basin and from the southern part of the basin (Mendeleev Plain) are included with Nautilus Basin. (b) Analysis of T-3 heat flow data as a function of surficial lithology as mapped by Boggild et al. (2018). Each lithology is predominantly, but not exclusively, associated with the province indicated, as shown in Table 3. 
Table 3

Percentage of T-3 Heat Flow Sites Associated With Each Type of Surficial Sediment by Physiographic Province

\begin{tabular}{|c|c|c|c|c|}
\hline & Alpha Ridge & Mendeleev Ridge & Canada Basin & $\begin{array}{c}\text { Nautilus Basin, including } \\
\text { Mendeleev Plain }\end{array}$ \\
\hline Turbidites (pelagic, planar) & 2 & 0 & 3 & 71 \\
\hline Turbidites/contourites (current influenced) & 0 & 0 & 93 & 0 \\
\hline Hemipelagic drape & 24 & 100 & 0 & 29 \\
\hline Deformed hemipelagic drape (impact structure?) ${ }^{\mathrm{a}}$ & 48 & 0 & 0 & 0 \\
\hline Mass transport/mass wasting deposits & 13 & 0 & 3 & 0 \\
\hline Erosional seafloor & 13 & 0 & 0 & 0 \\
\hline
\end{tabular}

Note. Sediment types from Boggild et al. (2018). Percentages may not sum to 100 due to rounding.

${ }^{\mathrm{a}}$ Kristoffersen et al. (2009). See area enclosed by black dashed curve in Figure 7.

Figure 4a shows all T-3 heat flow data split by physiographic province and plotted as a function of bathymetry. There is no clear large-scale correlation between heat flow and bathymetry either across the entire data set or within the Alpha or Mendeleev Ridge provinces or Canada Basin. In Nautilus Basin, the shallower southern area (Mendeleev Plain) has markedly lower heat flow than the deeper part of the basin, as discussed in further detail in section 5.2.4.

Figure $4 \mathrm{~b}$ splits the heat flow data based on the lithology of surface sediments as defined by Boggild et al. (2018), and Table 3 summarizes the surficial sediment lithologies at the locations of the heat flow measurements. Canada Basin (turbidites) and Mendeleev Ridge (hemipelagic drape) have nearly homogeneous surficial sediments, while Alpha Ridge hosts more varied sediments, including undeformed and deformed hemipelagic drape and erosional and mass transport deposits. The statistical modes of the heat flow data measured in areas mantled by turbidites (Nautilus and Canada Basin) and having thick sedimentary sections are higher than the modes for data from Mendeleev Ridge (hemipelagic drape) and Alpha Ridge, where deposits have variable thickness. Thick sediments sometimes reduce heat flow by insulating underlying basement and reducing the impact of basement heat flux. Sediment accumulations can also produce higher heat flow than bare basement when sediments are derived from rocks with elevated radiogenic heat content (e.g., from erosion of granitic continental rocks). Section 5 discusses heat flow for each physiographic province and explores the role of sediments and other factors in the observed heat flow variability for Amerasian Basin.

\subsection{Thermal Conductivity}

More than 780 interval (between thermistor) thermal conductivity averages are reported in Lachenbruch et al. (2019). Those average interval conductivities measured where interval geothermal gradients were also recorded are converted to SI units and plotted with heat flow measured at each site in Figure 5a. The average interval thermal conductivity for the data set is $1.125 \mathrm{~W} \mathrm{~m}^{-1} \mathrm{~K}^{-1}$, which is typical for saturated seafloor sediments (e.g., Pribnow et al., 2000). Values all lie within the range of 0.88 to $1.48 \mathrm{~W} \mathrm{~m}^{-1} \mathrm{~K}^{-1}$. The highest heat flow values in the data set correspond to thermal conductivities between 1.2 and $1.45 \mathrm{~W} \mathrm{~m}^{-1} \mathrm{~K}^{-1}$, and the lowest heat flow to thermal conductivities of 1.08 to $1.2 \mathrm{~W} \mathrm{~m}^{-1} \mathrm{~K}^{-1}$, meaning that thermal conductivity variations do play a role in heat flow, particularly for the higher values.

Average thermal conductivity $\left(K=1.26 \mathrm{~W} \mathrm{~m}^{-1} \mathrm{~K}^{-1}\right)$ for the interval between thermistors 3 and 4 is $15 \%$ higher than that for the deepest interval $\left(K=1.09 \mathrm{~W} \mathrm{~m}^{-1} \mathrm{~K}^{-1}\right)$ between thermistors 1 and 2 . This is the reverse of the typical trend of thermal conductivity increasing with depth below the seafloor as water content and porosity decrease, even over distances of a few meters. Since the thermal conductivity data were acquired in the laboratory on core sections, not within the seafloor with thermistors, it seems unlikely that a systematic instrumentation problem could produce this downhole thermal conductivity pattern. Arctic Ocean sediments are often deposited during repeated glacial cycles and may therefore not follow normal porosity-depth relationships that would lead to the typical downhole increase in thermal conductivity.

Figure 5b shows the binned interval thermal conductivities plotted by physiographic province. Alpha Ridge thermal conductivities are mostly higher than those on Mendeleev Ridge, but sediment type on Alpha Ridge is also more variable than the hemipelagic drape that dominates Mendeleev Ridge (Boggild et al., 2018), as shown in Table 3. Surficial sediments on Mendeleev and Alpha Ridge have consistently higher thermal conductivity than sediments in Nautilus Basin, whose northern part has the highest heat flow of any province. 
A.

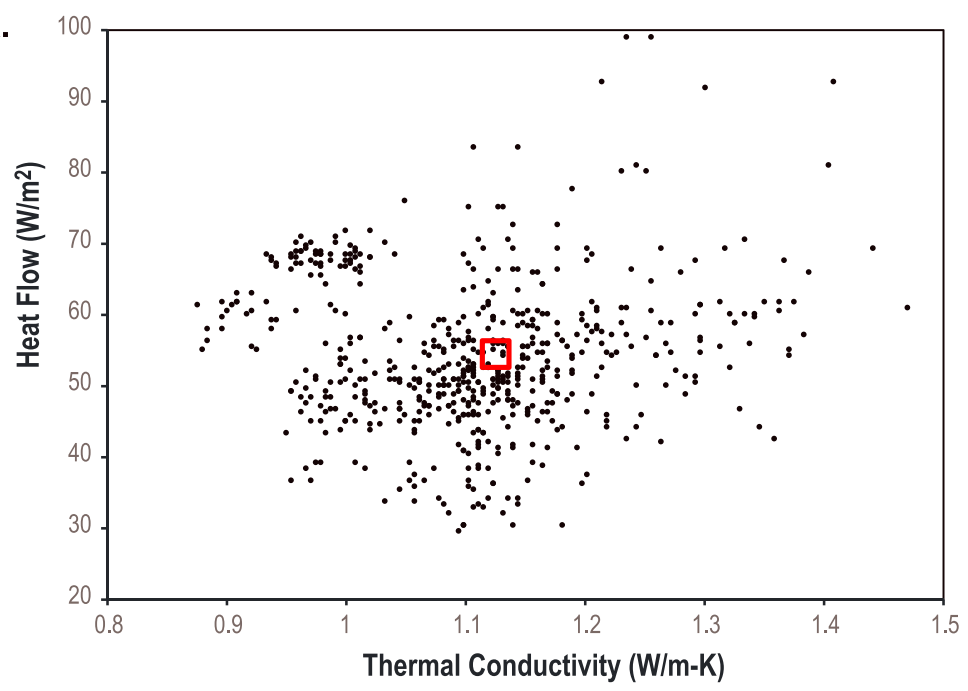

B.

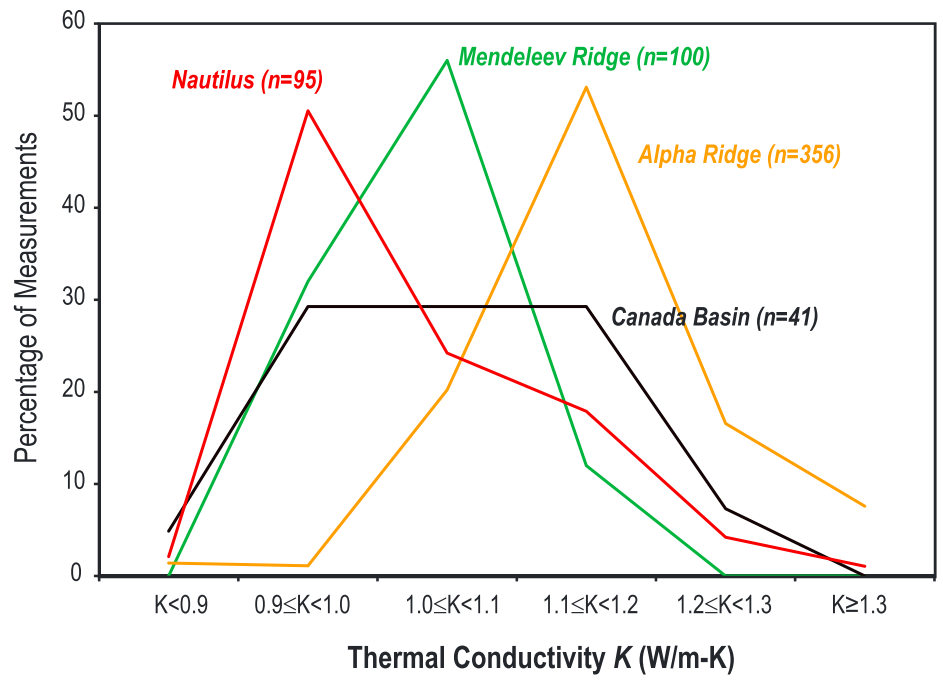

Figure 5. (a) The 592 interval thermal conductivities for intervals in which thermal gradients were also measured in the T-3 data set. Additional thermal conductivities were measured in intervals where no thermal gradients were obtained, but these are not plotted here. FL-389 (see caption for Figure 4) is omitted. The red square denotes the average binned thermal conductivity for the data set $\left(1.125 \mathrm{~W} \mathrm{~m}^{-1} \mathrm{~K}^{-1}\right)$. (b) Binned interval thermal conductivities recorded for intervals in which thermal gradients were measured, with results reported as a percentage of total measurements $n$ in each bin. Data from the Greenland-Canada margin are not included. The Nautilus Basin data include those from the Mendeleev Plain (southern Nautilus Basin).

This implies that at least part of the explanation for the difference in heat flow (section 4.1) among these physiographic provinces may be related to lower thermal gradients on AMR. The range of thermal conductivities measured on T-3 cores from Mendeleev Ridge and Nautilus Basin is wider (Figure 4b) than that determined for sediments on the East Siberian continental slope and shelf $(0.967 \pm 0.026$ to $1.099 \pm$ $0.107 \mathrm{~W} \mathrm{~m}^{-1} \mathrm{~K}^{-1}$, excluding the shallowest site at $120 \mathrm{~m}$ below sea level; O'Regan et al., 2016) using modern methods. The T-3 heat flow measurements likely encountered a wider range of sediment types than the O'Regan et al. (2016) study. The Canada Basin thermal conductivity distribution is different from that in the other physiographic provinces, with measured values for T-3 cores evenly distributed in the bins between 0.9 and $1.2 \mathrm{~W} \mathrm{~m}^{-1} \mathrm{~K}^{-1}$ (Figure $4 \mathrm{~b}$ ). The near-seafloor sediments in the Canada Basin are currentassociated turbidites (Table 3) according to Boggild et al. (2018), and the observed distribution of thermal conductivities may reflect the well-mixed nature of the sediments. 
A.

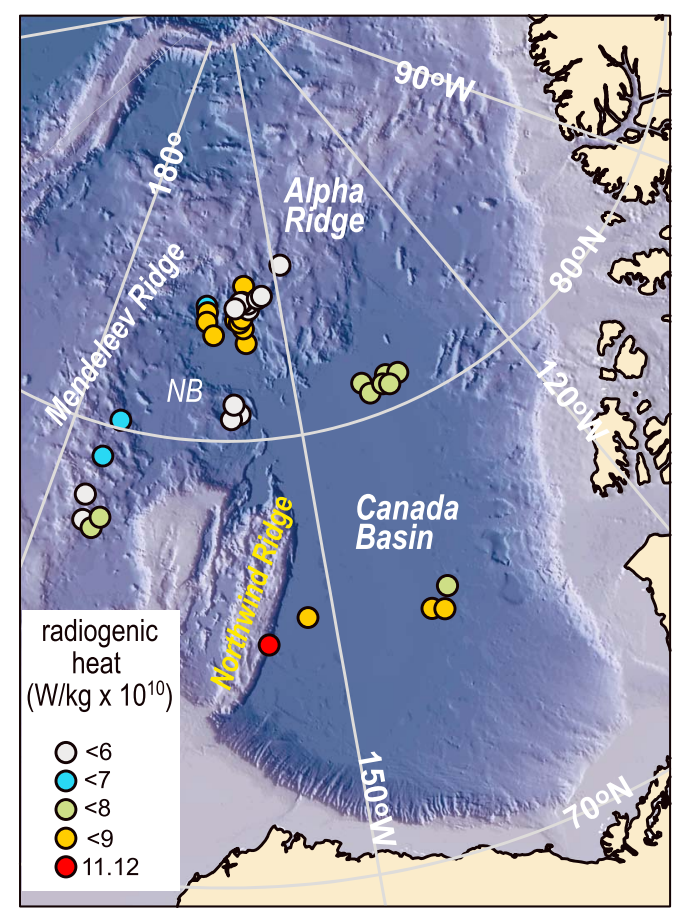

B.

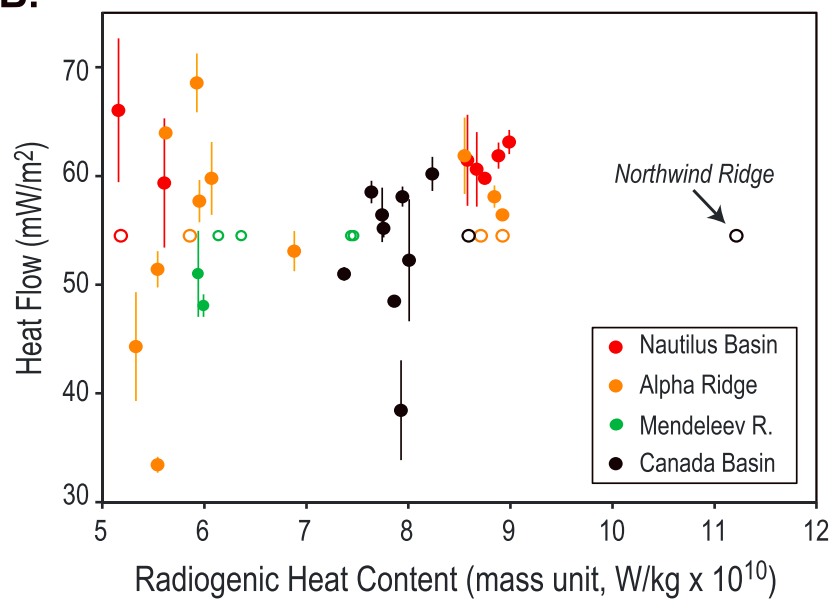

Figure 6. Radiogenic heat content measured in selected cores as reported by Lachenbruch et al. (2019). Results are given in SI mass units (W/kg) multiplied by $10^{10}$, as converted from the original units of $\mu \mathrm{cal} \mathrm{g}^{-1} \mathrm{yr}^{-1}$. (a) Color-coded map of locations where radiogenic heat content was measured in recovered cores. Heat flow was not recorded at all of these locations. NB denotes Nautilus Basin, the southern part of which is sometime referred to as the Mendeleev Plain. (b) Radiogenic heat content measured in recovered cores plotted with heat flow measured at those same penetrations, when available (solid circles). When no heat flow data are available, open circles are used for radiogenic heat content values plotted at the average heat flow for the whole data set. The circles are color coded by physiographic province as indicated on the legend.

\subsection{Thermal Gradients}

The emphasis in this study is mostly on heat flow determinations, where heat flow is given as the product of thermal conductivity $K$ and the measured thermal gradient. However, thermal gradient determinations that underpin heat flow calculations often reveal significant information about the thermal state of marine sediments. For $90 \%$ of the successful heat flow stations (306), two or more interval thermal gradient values are reported by Lachenbruch et al. (2019), meaning that $T_{e q}$ was determined at three or more thermistors. For $76 \%$ of these measurements, the standard deviation of the calculated interval thermal gradients at a single station is less than $5 \mathrm{mK} / \mathrm{m}$. Low standard deviation implies that the overall thermal gradient is close to linear, that thermal conduction dominates heat transfer, and that the sediments are likely in conductive thermal equilibrium with overlying seawater. The higher standard deviation for the remaining stations at which at least two interval thermal gradients are reported may in some cases indicate thermistor malfunction. For example, the deepest interval gradient at FL-556 through FL-562 is 17.8 to $37.7 \mathrm{mK} / \mathrm{m}$ less than that at the next shallowest interval, implying that thermistor 1 could have been faulty for these stations. Higher standard deviations could also reflect nonlinearities in gradients due to advective heat transfer or perturbed sediment temperatures near the seafloor due to changes in BWT (e.g., Ruppel et al., 1995).

The enhanced heat flow data set provided in Ruppel et al. (2019) includes plots of all the thermal gradients recorded by T-3. Fewer than $10 \%$ of the stations where at least three interval gradients are reported have bulk gradients that are either consistently concave down or concave up. More frequently, the middle of the three interval gradients is slightly higher than the gradients below or above over several consecutive heat flow stations, implying that the heat flow probe may have been encountering a laterally continuous layer of lower thermal conductivity in some locations.

\subsection{Radiogenic Heat Content}

The distribution of the 26 radiogenic heat content measurements made on recovered cores from each of the major physiographic provinces is shown in Figure 6a using the SI version of the heat mass units $\left(A_{m u}\right)$ reported by Lachenbruch et al. (2019). The highest value for the data set was obtained at the eastern boundary of Northwind Ridge at a location where no heat flow data were recorded. Cores from the northern, deeper part of Nautilus Basin and the adjacent part of Alpha Ridge consistently yielded the highest average radiogenic heat content. The lowest values were measured in cores from the southern, shallower part of Nautilus Basin adjacent to Chukchi Borderland (Mendeleev Plain) and on parts of Alpha Ridge. Mendeleev Ridge and Canada Basin values are intermediate.

The relationship between radiogenic heating and measured heat flow for each physiographic province is shown in Figure 6b. For the Canada Basin, the measured radiogenic heat content $A_{m u}$ is $\sim 8 \times 10^{-10} \mathrm{~W} / \mathrm{kg}$ in surficial sediments, and sediments are generally more than $5 \mathrm{~km}$ thick. If $A_{m u}$ were constant with depth, which is unrealistic, the sediments could contribute as much as $8 \mathrm{~mW} / \mathrm{m}^{2}$ to the measured heat flow assuming bulk sediment density of $2,000 \mathrm{~kg} / \mathrm{m}^{3}$. The northern Nautilus Basin (sediments several kilometers thick) to Alpha Ridge (thin sediments) transition has some locations with similar $A_{m u}$ and high measured heat flow, but the contribution from radiogenic heating would be proportionally smaller for thinner sediments. Thus, radiogenic heat from shallow sediments may not be a major contributor to elevated heat flow measurements in the T-3 data set. One caveat is that parts of the study area are underlain by 
magmatic material that may have mixed with continental crustal components (e.g., Jackson et al., 2018; Oakey \& Saltus, 2016). This material may have higher radiogenic heat content than oceanic basalts and could contribute to measured heat flow in these areas.

\section{Discussion}

The following sections interpret the T-3 heat flow data through comparisons with heat flow measurements and other geophysical (primarily seismic) data sets not available until after 2000. In addition, we construct a simple conductive thermal model for the Amerasian Basin to examine first-order variations in the T-3 data set.

\subsection{T-3 Data and Other Arctic Heat Flow Data Sets}

Heat flow data from T-3 are combined with measurements from other surveys in Figure 2. Most Arctic Ocean heat flow data acquired in the four decades between the start of the T-3 expedition and the early 2000s were collected offshore Greenland and Norway or close to the Canadian Arctic Islands (e.g., Louden et al., 1990; Paterson \& Law, 1966), not in the central Amerasian Basin. Many of these data were compiled in the Global Heat Flow database (IHFC, 2012) and described in Langseth et al. (1990). One survey that overlaps with the larger T-3 study area is described by Taylor et al. (1986) and was collected from an ice camp during the Canadian Expedition to Study the Alpha Ridge (CESAR). However, the CESAR sites are all contained within an $\sim 50-\mathrm{km}^{2}$ area on Alpha Ridge, $\sim 40 \mathrm{~km}$ from the nearest T-3 measurement (FL-479). During research that was contemporaneous with the T-3 expedition, Lubimova et al. (1973) collected more than 30 measurements on the East Siberian margin, between AMR and Lomonosov Ridge in Makarov Basin, and even at one site within Canada Basin.

Since 2000, several shipboard piston coring programs have acquired coincident heat flow data within the Amerasian Basin and on its periphery, producing data that either complement or overlap the geographical coverage of T-3 data. These data include those collected on the icebreaker Oden on the East Siberian continental slope and the east Lomonosov Ridge (O'Regan et al., 2016); across Mendeleev Ridge on the Polarstern during ARK-XXIII/3 (Jokat, 2009); and for two locations near Alpha Ridge and one in Canada Basin, as well as previously unpublished data that include some sites in the Amerasian Basin (Shephard et al., 2018). Additional heat flow programs carried out on the Lomonosov Ridge (Xiao et al., 2013) and Gakkel Ridge (Urlaub et al., 2009) have increased the number of data for the Eurasian Basin part of the Arctic Ocean, but are not considered further here.

Only one set of T-3 heat flow stations is within $20 \mathrm{~km}$ of more recent measurements made in the Arctic Ocean. T-3 measurement FL-224 described in Lachenbruch et al. (2019) lies 250-300 m from HF0802A01 (3599-m water depth) and -A02 (3,607 m), where heat flow was determined by Jokat (2009) in 2008. Reported heat flow values for the modern measurements are 60 and $57 \mathrm{~mW} / \mathrm{m}^{2}$, respectively, based on an assumed $K$ of $1.0 \mathrm{~W} \mathrm{~m}^{-1} \mathrm{~K}^{-1}$. These heat flow values from Jokat (2009) would be even higher if the $K$ value determined at FL-224 $\left(1.12 \mathrm{~W} \mathrm{~m}^{-1} \mathrm{~K}^{-1}\right)$ were used with the Polarstern thermal gradients, yielding 66.8 and $64.3 \mathrm{~mW} / \mathrm{m}^{2}$. For comparison, the T-3 expedition measured $51.8 \pm 1.4 \mathrm{~mW} / \mathrm{m}^{2}(3,468-\mathrm{m}$ water depth) at FL224. Five T-3 heat flow sites (including FL-224) within $12 \mathrm{~km}$ of the Jokat (2009) heat flow determinations average $58.6 \pm 4.8 \mathrm{~mW} / \mathrm{m}^{2}$, which is indistinguishable from the uncorrected Polarstern values. These heat flow measurements were made in isolated submarine highlands that form the southern part of Nautilus Basin (Mendeleev Basin) where bathymetry shoals by several hundred meters (Jakobsson et al., 2003), possibly on a rocky protrusion where sediment thicknesses are likely to be spatially variable.

\subsection{Heat Flow by Physiographic Region}

T-3 measurements combined with other Arctic Ocean heat flow data can be used to analyze heat flow variations along modern seismic lines where basement structure, sediment distribution, and other features have been inferred or imaged. In the next section, we focus on heat flow transects through parts of Mendeleev and Alpha Ridges and in Nautilus and Canada basins. T-3 heat flow measurements taken at distances up to 30 $\mathrm{km}$ from geophysical transects are projected onto profiles to support the analysis of heat flow variations. An important caveat is that heat flow data from so far off a selected profile may not accurately reflect the local structure given the degree of lateral heterogeneity in geology, basement faulting, and sediment thickness in some parts of the Amerasian Basin. 


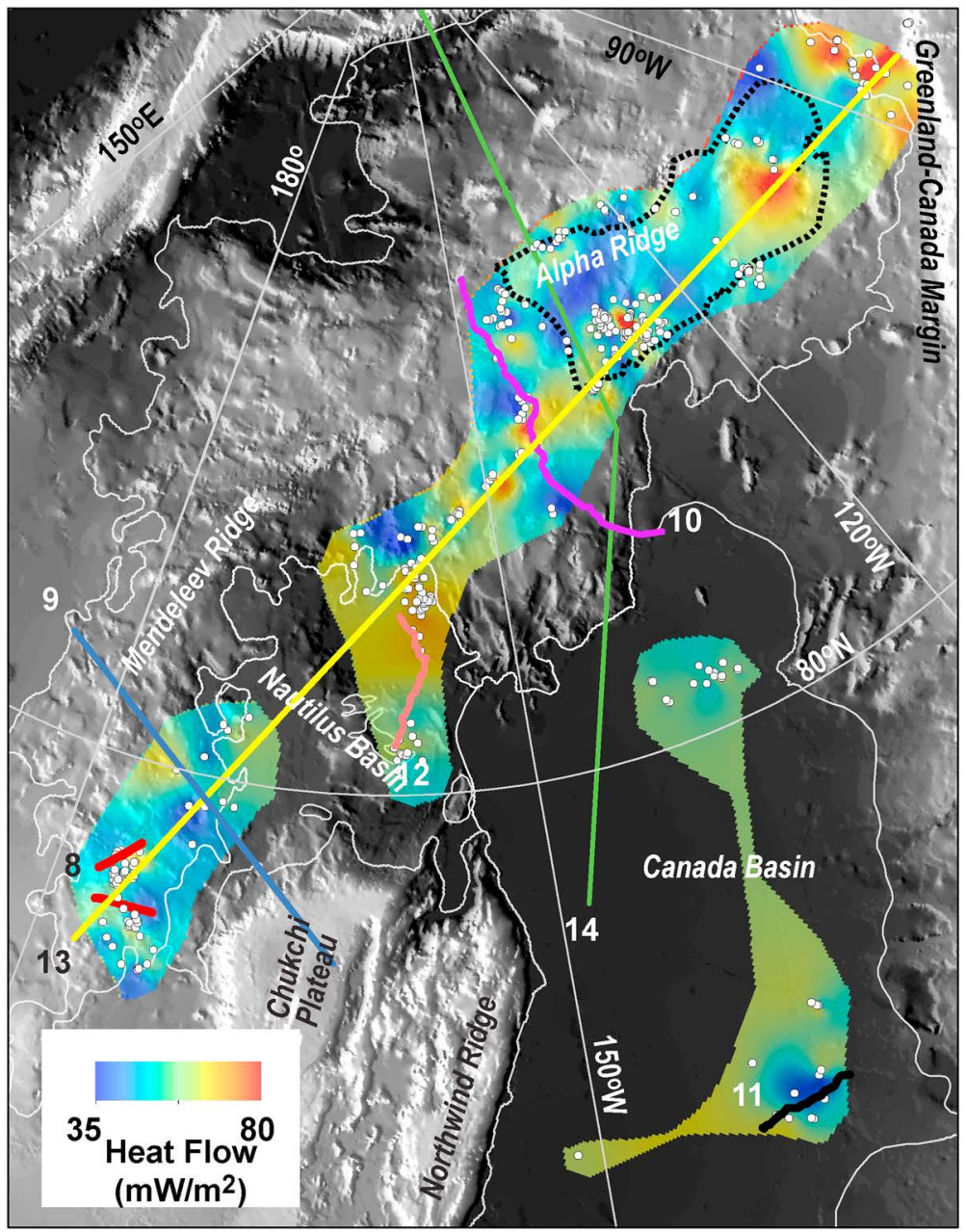

Figure 7. Gridded T-3 heat flow data in areas of sufficient data density were used to generate the underlying color coded map in ArcGIS. The area enclosed by the black dashed outline corresponds to deformed hemipelagic sediments as mapped by Boggild et al. (2018) at the same location as a possible extraterrestrial impact structure by Kristoffersen et al. (2009). The profiles are labeled with numbers corresponding to Figures 8-13, which depict other data (e.g., bathymetry, seismics) along with the proximal T-3 heat flow measurements. The profile labeled 14 shows the location of the crustal model from Oakey and Saltus (2016) used in the calculations shown in Figure 14.

\subsubsection{Mendeleev Ridge}

Portions of multichannel seismic (MCS) lines 18 and 20 acquired on the USCG Healy in 2005 (Bruvoll et al., 2010; Dove et al., 2010) as part of the HOTRAX program overlap with areas where T-3 heat flow data were collected on the eastern side of Mendeleev Ridge. Figure 7 shows the locations of these lines, and Figure 8 depicts the migrated MCS data (Coakley et al., 2005), along with T-3 heat flow points within $20 \mathrm{~km}$ of the seismic lines.

Line 18 was acquired from east to west across the southernmost part of Mendeleev Ridge and images evenly bedded sediment hundreds of meters thick. The underlying volcanic basement is faulted, but relatively smooth (Bruvoll et al., 2010), and has fewer large offset faults than imaged on some other parts of Mendeleev Ridge (e.g., Butsenko et al., 2019). Four T-3 measurements (FL-123 to FL-126) lie within 20 $\mathrm{km}$ of the MCS line and are associated with heat flow ranging from 39.3 to $53.9 \mathrm{~mW} / \mathrm{m}^{2}$, with variations roughly following bathymetry. The continuous sediments on this transect vary in thickness by only $\sim 60$ $\mathrm{m}$, meaning that sediment thickness changes (e.g., either less blanketing of the basement or more radiogenic heat produced within the sedimentary section) is an unlikely explanation for heat flow variations. Closer analysis of the heat flow data shows that the lowest measurement (FL-124) is associated with a $K$ value that is more than $10 \%$ smaller $\left(0.9 \mathrm{~W} \mathrm{~m}^{-1} \mathrm{~K}^{-1}\right)$ than that at the adjacent points. Using the average 

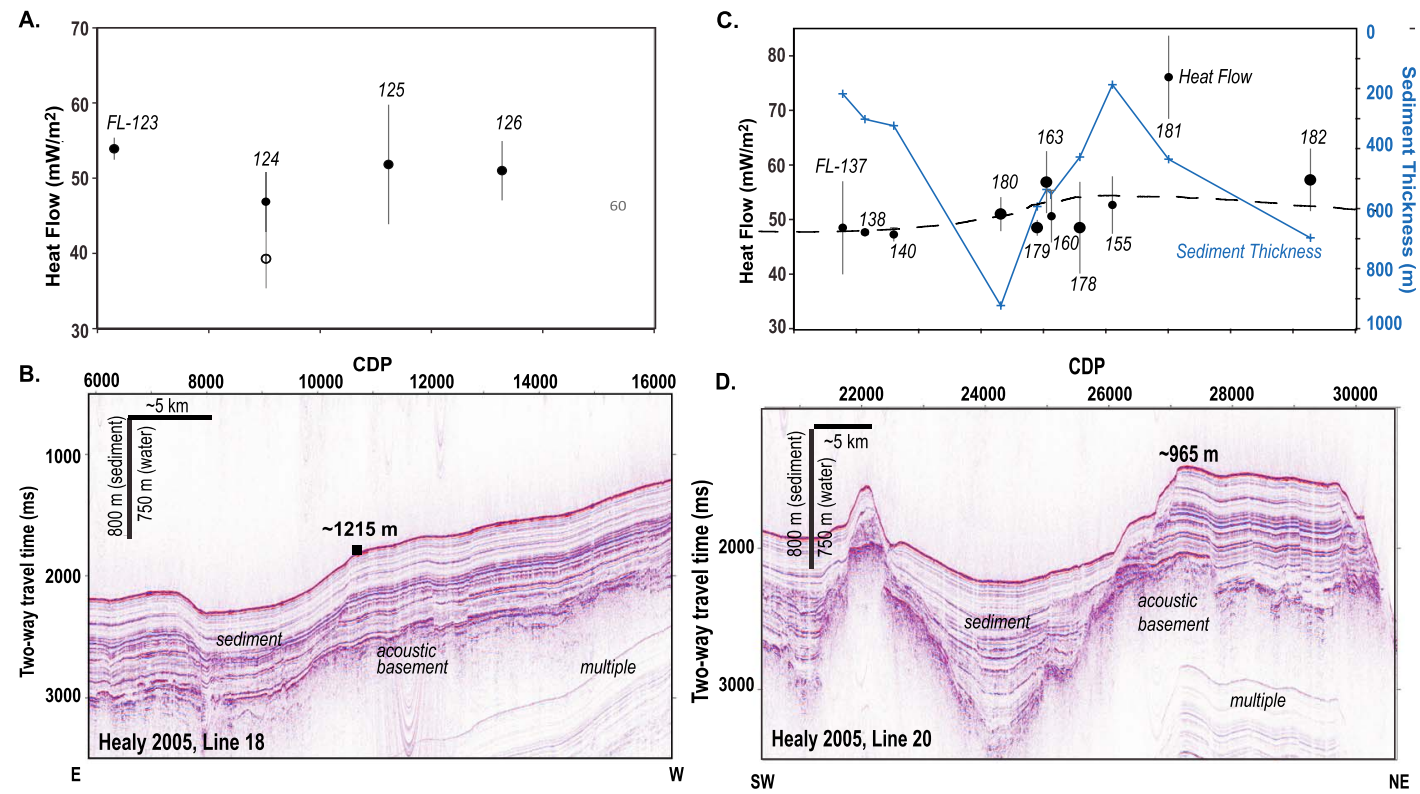

Figure 8. (a and c) Mendeleev Ridge T-3 heat flow measurements and associated uncertainties along portions of the 2005 Healy multichannel seismic (MCS) lines (b) 18 and (d) 20 (Coakley et al., 2005), respectively. The labels on the heat flow points correspond to the measurement number in the T-3 data set (Lachenbruch et al., 2019; Ruppel et al., 2019). The dashed curve in (c) is extracted from the gridded data shown in Figure 7. The open circle in (a) for FL-124 indicates the original heat flow value, which would be higher (closed circle) once corrected with thermal conductivity recorded at adjacent sites. Part (c) also shows the thickness of sediment (blue) along the profile as calculated by measuring the TWTT to basement from the seismic data and converting to thickness using an assumed seismic velocity of $1,600 \mathrm{~m} / \mathrm{s}$. Numbers in (b) and (d) indicate nominal water depth at the indicated points on the seafloor. CDP refers to common depth point from (Coakley et al., 2005). Profile locations are shown in Figure 7.

$K\left(1.007 \mathrm{~W} \mathrm{~m}^{-1} \mathrm{~K}^{-1}\right)$ at the adjacent measurements increased the heat flow value to $46.7 \mathrm{~mW} / \mathrm{m}^{2}$, rendering heat flow along this transect nearly constant within the uncertainties.

Healy 0503 MCS Line 20 was acquired from southwest to northeast and crosses two local bathymetric highs and an intervening graben within the southern Mendeleev Ridge. The acoustic basement is more faulted than on Line 18, and sediment thickness varies between 200 and nearly 1,000 m. Eleven T-3 measurements lie within $20 \mathrm{~km}$ of the portion of the MCS line shown in Figure 8d, including FL-163 within $300 \mathrm{~m}$, FL-178 to FL-180 and FL-183 within 3.6 to $8 \mathrm{~km}$, and other stations at 11.4 to $19.9 \mathrm{~km}$ distance. Sediment thicknesses measured from the MCS data at the locations of the projected T- 3 measurement sites do not reveal any correlation with heat flow variations. In fact, sediment thickness is more than double (865-980 m, estimated using seismic velocity of 1,600 m/s for near-seafloor sediment; Shimeld et al., 2016) at FL-180 compared to that at FL-178 (401-455 m) yet the heat flow values are indistinguishable $\left(51.0 \pm 3.1 \mathrm{~mW} / \mathrm{m}^{2}\right.$ at FL-180 compared to $48.5 \pm 8.4 \mathrm{~mW} / \mathrm{m}^{2}$ at FL-178). Figure $8 \mathrm{c}$ shows that heat flow increases from an average of $51.5 \mathrm{~mW} / \mathrm{m}^{2}$ in the graben to $76.1 \mathrm{~mW} / \mathrm{m}^{2}$ on the slope climbing out of the graben and then decreases to $57.3 \mathrm{~mW} / \mathrm{m}^{2}$ near the top of the bathymetric high to the northeast. Locally elevated heat flow may be an edge effect associated with lateral heterogeneity in the arrangement of the basement (see section 5.3) and overlying sediment. This heat flow pattern may also reflect fluid expulsion at the edge of the graben, possibly facilitated by faults that disrupt the volcanic basement.

Some T-3 heat flow data also lie close to Arktika MCS Line 2012-04 described by Butsenko et al. (2019) based on earlier work by Nikishin et al. $(2015,2017)$. Because the navigation and digital seismic data have not been published for this line, the location of the transect was inferred by georeferencing the Butsenko et al. (2019) map in ArcGIS software and then roughly matching the bathymetry from the seismic line to IBCAO bathymetry (Jakobsson et al., 2012). Figure 9 shows the Butsenko et al. (2019) interpretation of the seismic data along with the T-3 heat flow sites that lie near the line on the east side of Mendeleev Ridge. The heat flow values along the track vary between 36.8 and $63.1 \mathrm{~mW} / \mathrm{m}^{2}$, and these minimum and maximum values are recorded at adjacent sites separated by $\sim 40 \mathrm{~km}$. The highest heat flow value (refraction effect?) was 


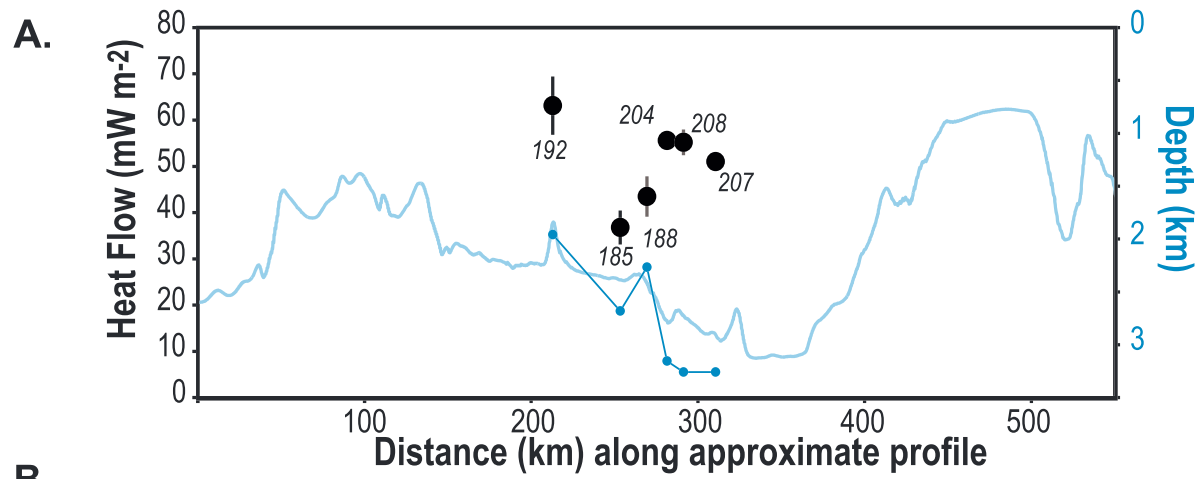

B.

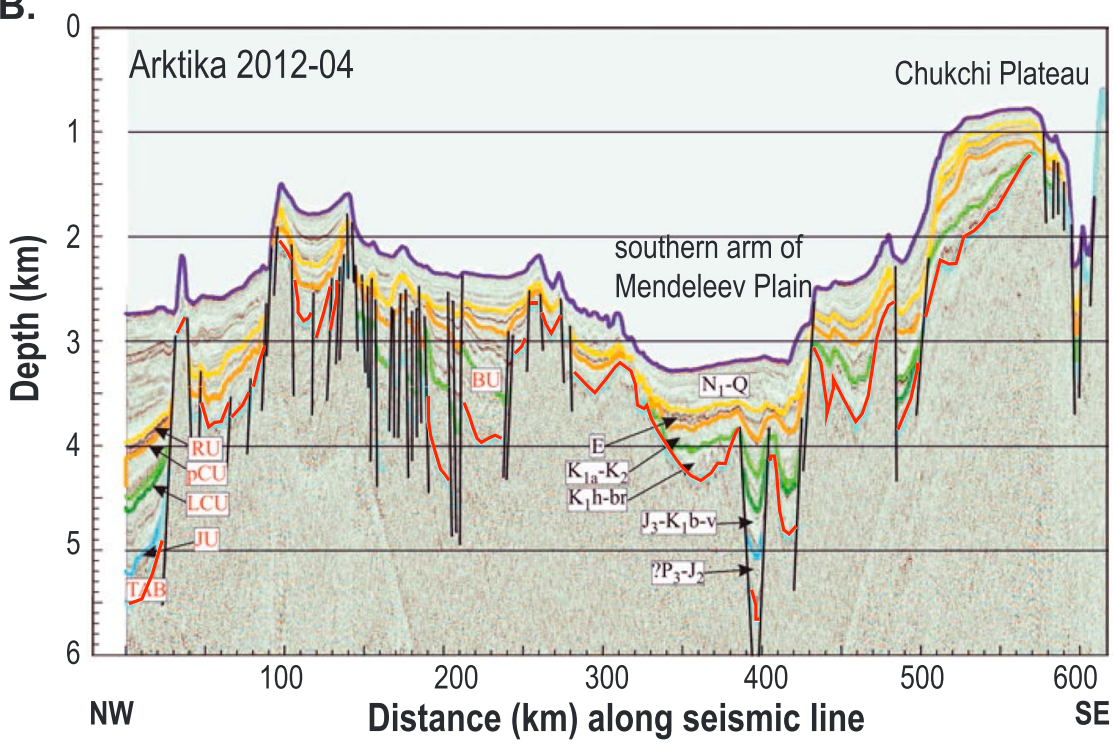

Figure 9. (a) Eastern Mendeleev Ridge T-3 heat flow (black points, labeled with station number) with uncertainties (left axis) and bathymetry (right axis) and (b) MCS data and interpreted geology from Butsenko et al. (2019) along a portion of the Artika 2012-04 profile. The seismic profile was depth-converted by the original authors. Lacking navigational information for the Artika line, this profile was georeferenced from a published map using ArcGIS. The bathymetry from independent data sets was used as a check on the quality of the georeferencing. In (a), the continuous light blue curve is bathymetry extracted from the IBCAO database (Jakobsson et al., 2012) along the path of the georeferenced transect. The darker blue connected points are bathymetric measurements recorded by Lachenbruch et al. (2019) at the locations of the heat flow sites. Profile location shown in Figure 7.

measured on a bathymetric high underlain by a horst-like structure in the basement of the easternmost Mendeleev Ridge (FL-192; Figure 9a), and the lowest value was recorded $\sim 50 \mathrm{~km}$ to the east (FL-185; Figure 9a). Farther east, heat flow increases along the edge of Mendeleev Plain (Figure 2). The three measurements within Mendeleev Plain (FL-204, 207, and 208) average $54.3 \mathrm{~mW} / \mathrm{m}^{2}$, close to the average for the T-3 data set and similar to the values measured in the intraridge basin along Healy MCS line 20, as described above. The overall pattern of heat flow variations suggests elevated heat flow in thicker sediments and a possible role for fluid circulation through basement faults for other locations.

\subsubsection{Alpha Ridge}

The largest subset of T-3 heat flow data was collected on Alpha Ridge. Unfortunately, modern seismic surveys on Alpha Ridge do not cross the areas of dense heat flow measurements. Lamont Geological Observatory intermittently collected seismic reflection data along the exact drift path of T-3, sometimes coincident with the heat flow data. However, the publicly available scanned paper records (Hunkins \& Tiemann, 1977) are not legible, and higher-quality scans of the original rolls of seismic data (J. K. Hall, personal communications, 2018) were not complete enough to assist in interpreting T-3 heat flow data on Alpha Ridge. For these reasons, the analysis of Alpha Ridge T-3 heat flow data in terms of underlying structure relies on 3.5-kHz subbottom profiling data obtained by the Oden in 2016 (extracted from Boggild et al. (2018)). 

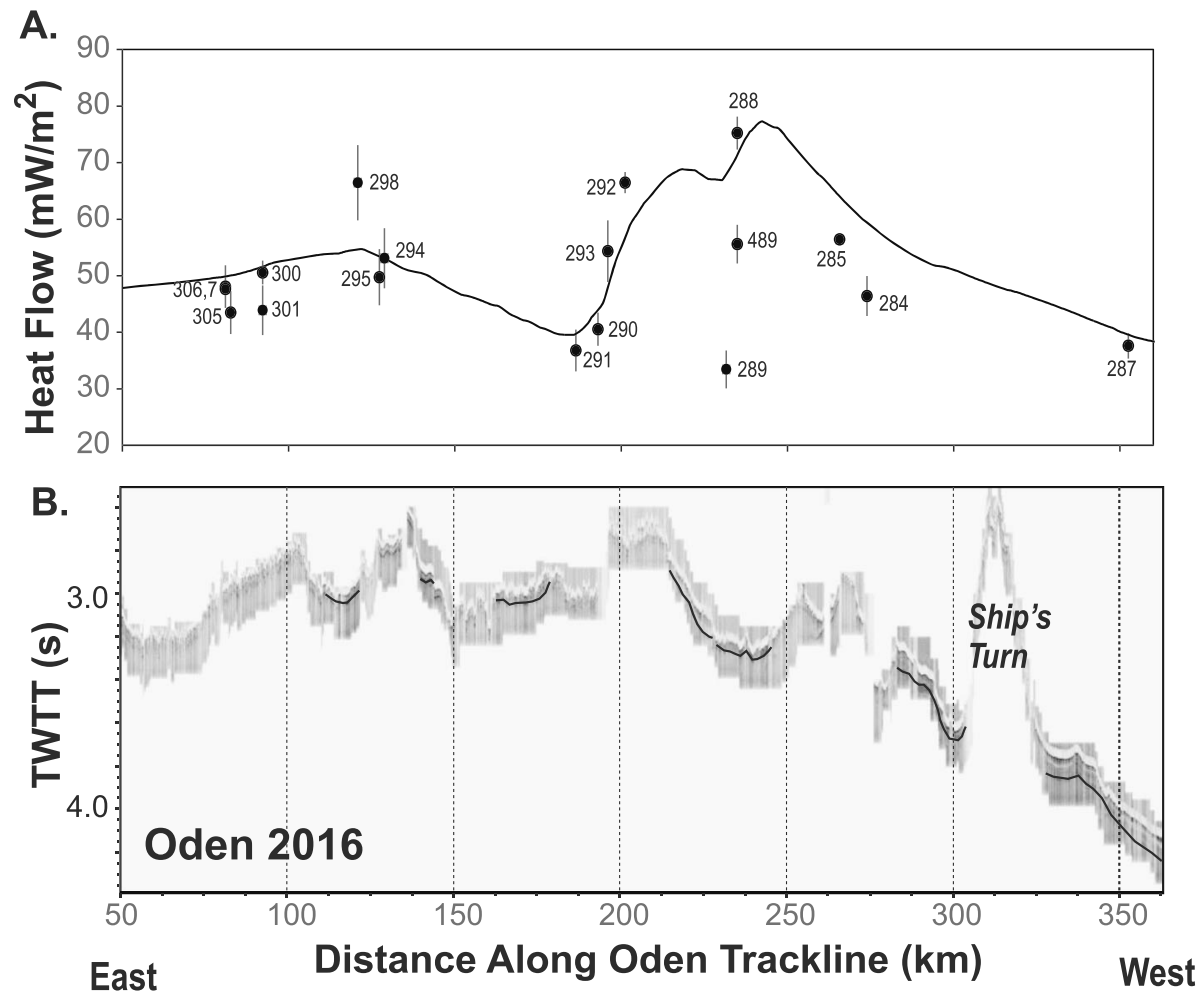

Figure 10. (a) Alpha Ridge T-3 heat flow measurements (black points) with uncertainties and the smoothed heat flow (black curve) extracted from the gridded data shown in Figure 7. (b) Subbottom profiler data were collected on this transect by the Oden in 2016 and are here taken from the compilation of Boggild et al. (2018). Black curves show the base of well-imaged surficial sediments, but the data may not image the entire sedimentary section in some places. TWTT denotes two-way travel time from vessel to seafloor. Profile location shown in Figure 7.

Figure 10 shows heat flow data within $30 \mathrm{~km}$ of the 2016 Oden ship track (location in Figure 7) projected onto an Alpha Ridge transect. The subbottom profiler data appear to image thin sediment veneer (generally less than $100 \mathrm{~m}$ ) over basement, although the high-frequency signal from the profiler may not have reached the base of sediments in some locations. Some of the lowest $\left(<40 \mathrm{~mW} / \mathrm{m}^{2}\right)$ and highest $\left(>70 \mathrm{~mW} / \mathrm{m}^{2}\right)$ Alpha Ridge heat flow values are measured near the Oden transect, and sequential measurements FL-288 and FL289 illustrate the juxtaposition of high and low values.

Heat flow variations along this Alpha Ridge transect do not correlate with changes in bathymetry. Heat flow is on average lower over the shallower relief on the east side of the profile, rises over the interridge basin at 210-250-km distance, and then decreases on the western flank as bathymetry also deepens. The increased heat flow within the interridge basin may be related to the changing bathymetry, lithologies of different thermal conductivities on adjacent parts of the ridge, and/or faulted basement channeling fluids near the edge of the basin. Section 5.3 explores some of these factors in more detail for a profile that includes the densest collection of T-3 measurements on Alpha Ridge.

\subsubsection{Canada Basin}

Canada Basin T-3 heat flow data cluster in two areas that are, respectively, more than $5 \times 10^{4}$ and $10^{5} \mathrm{~km}^{2}$ in size. Seismic lines that have been acquired in the regions of the Canada Basin surveyed by T-3 since 2000 are widely spaced and do not intersect many of the T-3 heat flow data (e.g., Mosher \& Hutchinson, 2019). Figure 11 shows T-3 heat flow data measured within $22 \mathrm{~km}$ of an air gun seismic line collected in the Canada Basin in 2007 by the Louis St. Laurent in an area with sediment thickness greater than $6 \mathrm{~km}$ (Boggild et al., 2018; Shimeld et al., 2016). The two westernmost heat flow points average $59.8 \mathrm{~mW} / \mathrm{m}^{2}$ with $K$ of $0.93 \mathrm{~W} \mathrm{~m}^{-1} \mathrm{~K}^{-1}$ and radiogenic heat production $A_{m u} 8.24 \times 10^{-10} \mathrm{~W} / \mathrm{kg}$ that was measured at FL- 66 . The five easternmost points have average heat flow of $45.1 \mathrm{~mW} / \mathrm{m}^{2}$ and average $K$ of $1.05 \mathrm{~W} \mathrm{~m}^{-1} \mathrm{~K}^{-1}$ with $A_{m u}$ is $7.93 \times 10^{-10} \mathrm{~W} / \mathrm{kg}$ at FL-74. Sediments are flat-lying and undeformed along the transect. However, 
A.
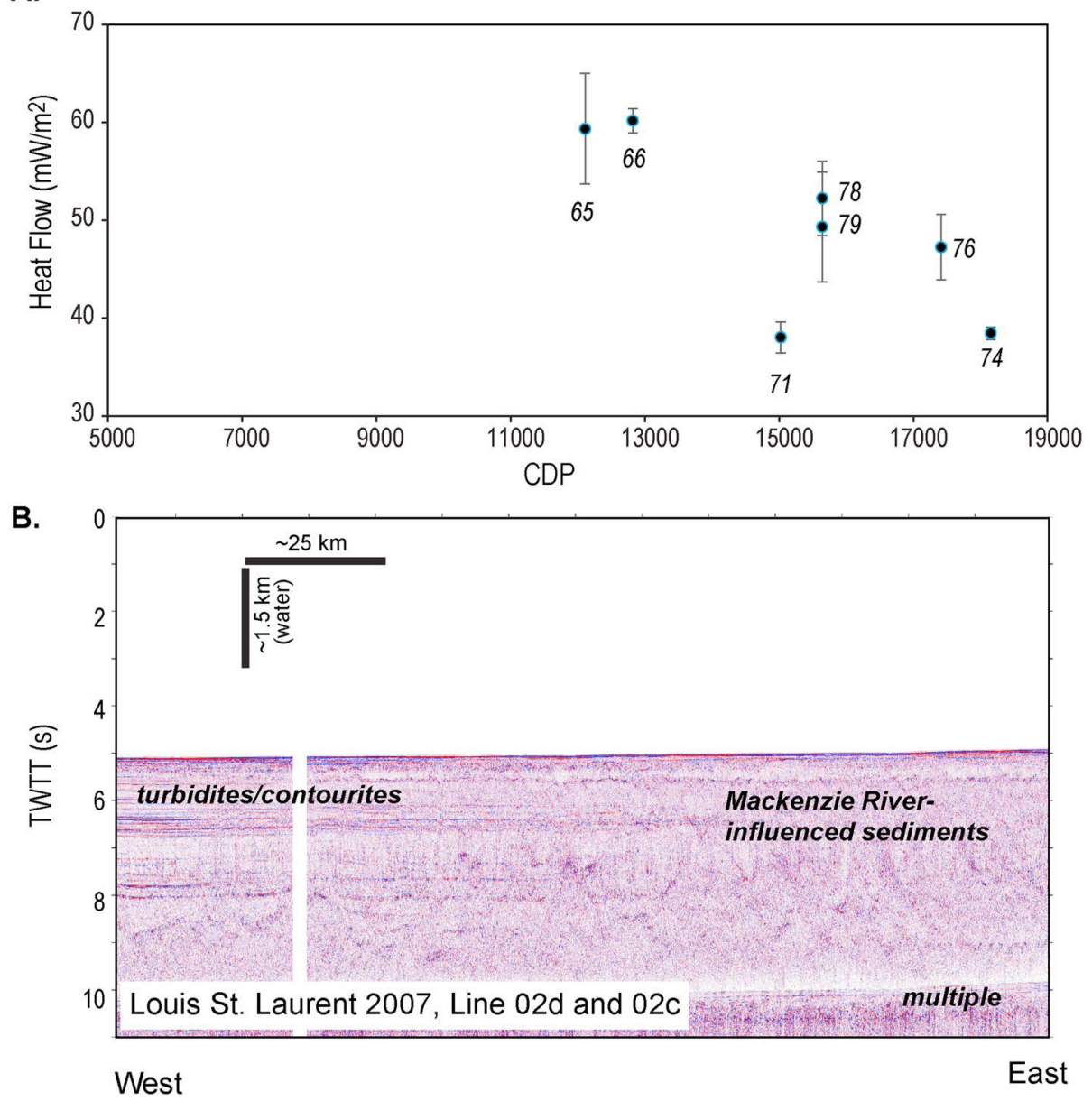

Figure 11. Northern Canada Basin (a) labeled T-3 heat flow measurements with uncertainties and (b) MCS data collected by the Louis St. Laurent in 2007. CDP denotes common depth point as assigned by the Extended Continental Shelf Project, and TWTT is two-way travel time from vessel to seafloor. Profile location shown in Figure 7.

the seismic character of the deeper sedimentary package shifts: sediments on the western side and in the center of the profile are likely turbidites and/or contourites, which are found throughout the Canada Basin, while the sediments on the eastern side of the profile (more irregular reflectivity) have been more strongly influenced by the Mackenzie River (Mosher \& Hutchinson, 2019). Whether heat flow variations at the seafloor are related to changes in the deeper sedimentary section is unknown. Even for the surficial sediments, the thermal conductivity increases by $\sim 13 \%$ between the center and east sides of this profile, while the thermal gradients decrease. Coarser-grained silts like those found at FL-78 (Clark et al., 1980) in the southern cluster of Canada Basin T-3 sites more proximal to the Mackenzie River sediment plume should have higher thermal conductivity than finer-grained clays (Clark et al., 1980) that dominate at FL50 in the northern cluster of Canada Basin sites (Figure 2). Higher thermal conductivity can lead to lower conductive thermal gradients. Heat flow variations across the apparent sediment transition along this seismic profile may reflect changes in thermal conductivity.

\subsubsection{Nautilus Basin}

Along with parts of Alpha Ridge, the northern part of Nautilus Basin is the most densely surveyed area in the T-3 data set. Figure 12 shows a 3.5-kHz Chirp subbottom profile collected from south to north in Nautilus Basin on the Louis St. Laurent in 2016 and T-3 heat flow data acquired within $20 \mathrm{~km}$ of this transect. As is evident from the gridded data in Figure 7, average heat flow is at least 25\% higher on the flat seafloor in northern Nautilus Basin adjacent to Alpha Ridge than for the shallower, variable relief seafloor in the southern basin (Mendeleev Plain). Radiogenic heat content was not measured for the exact heat flow sites that 


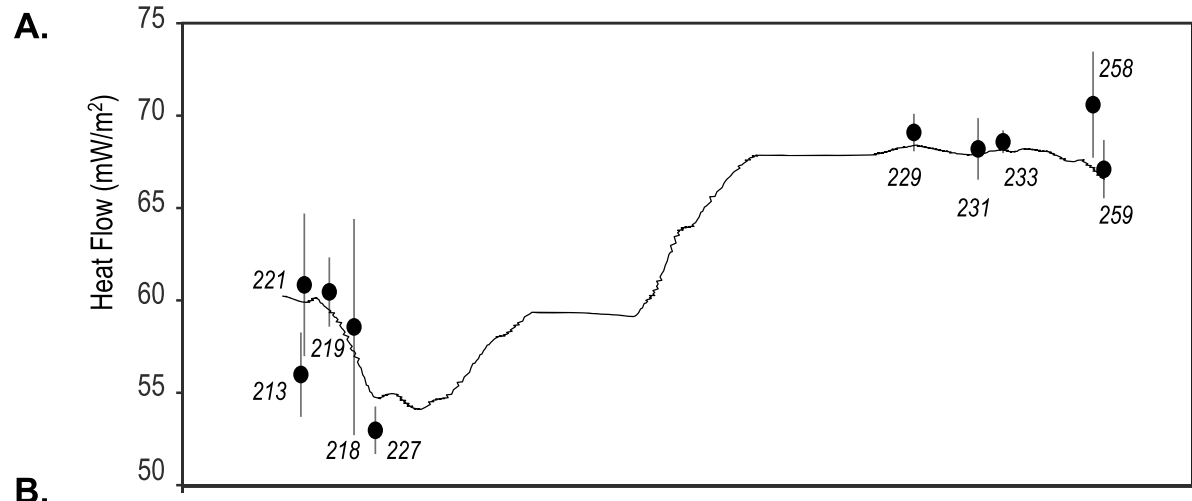

B.

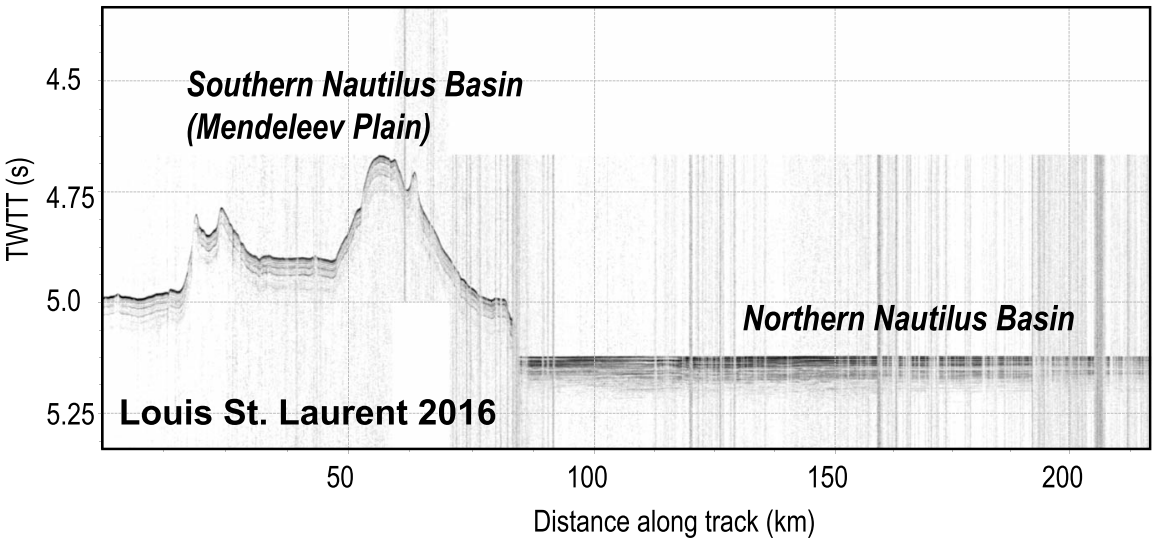

Figure 12. Nautilus Basin (a) labeled T-3 heat flow data with uncertainties (points) and smoothed heat flow (black curve) extracted from the gridded data along the profile shown in Figure 7. (b) Subbottom profile collected by the Louis St. Laurent in 2016. Data extracted from compilation of Boggild et al. (2018). The southern Nautilus Basin is also called the Mendeleev Plain. TWTT denotes two-way travel time from vessel to seafloor.

project onto this Chirp line. However, the northern Nautilus Basin heat flow points in Figure 12 are within $50 \mathrm{~km}$ of and in the same part of the basin as FL-2, 3, 6, 8, and 9 (average $A_{m u}=8.88 \times 10^{-10} \mathrm{~W} / \mathrm{kg}$ ), and the southern Nautilus Basin (Mendeleev Plain) heat flow points are at or near FL-217, 222, and 228, where average $\mathrm{A}_{m u}$ is measured at $5.3 \times 10^{-10} \mathrm{~W} / \mathrm{kg}$. If sediments in the northern Nautilus Basin are $2 \mathrm{~km}$ thick, as inferred from Mosher and Hutchinson (2019), and have constant radiogenic heat content, then the sediments could contribute a maximum of $3.7 \mathrm{~mW} / \mathrm{m}^{2}$ to the measured heat flow (average $68.7 \mathrm{~mW} / \mathrm{m}^{2}$ for points shown in Figure 12) even assuming a relatively high value for sediment density $\left(2,100 \mathrm{~kg} / \mathrm{m}^{3}\right)$. The sediments on southern Nautilus Basin (Mendeleev Plain), where weathered basalt and volcaniclastic rocks were dredged in 2008 (Brumley et al., 2015), are less than a few hundred meters thick. Radioactive heating would contribute less than $1 \mathrm{~mW} / \mathrm{m}^{2}$ to the measured heat flow (average $57.8 \mathrm{~mW} / \mathrm{m}^{2}$ for points in Figure 12) on this part of the transect. Differences in sediment thickness and heat production can therefore not fully explain the variations in heat flow across Nautilus Basin. Other factors, including proximity of the northern basin to Alpha Ridge and to the complex lithology that underlies it, likely play a critical role in the observed heat flow pattern, as discussed by Lachenbruch and Marshall (1966) and modeled in section 5.3.

\subsection{Factors Contributing to Heat Flow Variability}

The average heat flow for the $356 \mathrm{~T}-3$ heat flow determinations $\left(54.7 \pm 11.3 \mathrm{~mW} / \mathrm{m}^{2}\right)$ is consistent with oceanic crust formed at $\sim 77 \mathrm{Ma}$ (Parsons \& Sclater, 1977) and $100 \mathrm{Ma}$ (Stein \& Stein, 1992), depending on the heat flow versus age model adopted. However, almost none of the measurements, not even most of those in Canada Basin, were acquired in areas with normal oceanic crust produced at a spreading center. Especially AMR and parts of Nautilus Basin may be underlain by magmatic material generated during the emplacement of HALIP (e.g., Chian et al., 2016; Døssing et al., 2013; Forsyth et al., 1986; Funck et al., 2011; Gaina et al., 2014; Jackson et al., 1986; Lebedeva-Ivanova et al., 2006; Oakey \& Saltus, 2016). 
The T-3 heat flow data were collected in an intraplate location within an ocean basin with a complex tectonic history, in contrast to heat flow data sets that target special tectonic settings (e.g., mid-ocean ridge, subduction zone, or passive continental margin). Thus, no unifying theoretical framework for heat flow variations as a function of distance from plate boundaries or age of underlying crust can be readily applied to the T-3 data set. More than 45 years after the last T-3 data were acquired, the ongoing lack of geophysical data in much of the study area also frustrate attempts to analyze the pattern of either large-scale (e.g., Nautilus Basin versus AMR) or local variations in the T-3 heat flow data.

Heat flow patterns associated with hot spot plumes and resulting LIPs have been systematically analyzed in some locations and could provide a basis for examining heat flow from AMR. Stein and Stein (1993) and Stein and Von Herzen (2007) review data from hot spot bathymetric swells in the Atlantic, Pacific, and Indian Oceans and interpret the heat flow as being normal or only slightly elevated at these locations relative to the predictions of reference models (Stein \& Stein, 1992) that link ocean crustal age to seafloor depth and heat flow. The AMR likely originated as preexisting lithosphere interacted with one or more (Oakey \& Saltus, 2016) mantle plumes to produce HALIP. Average T-3 heat flow values on Alpha Ridge and Mendeleev Ridge (Table 2) are, respectively, about the same as those in Canada Basin and less than 10\% lower than those in Canada Basin. Heat flow for both ridges has significant uncertainties (greater than $20 \%$ for Alpha Ridge and 10\% for Mendeleev Ridge). These heat flow observations, coupled with the unknown composition of the preexisting AMR crust (e.g., Oakey \& Saltus, 2016) and the fact that the age of the crust (if oceanic) cannot be discerned from magnetic anomalies (Funck et al., 2011), render it impossible to determine whether the T-3 heat flow data are normal for such crust after passage of a hot spot plume.

Before any modern seismic data had been acquired or potential field studies completed, Lachenbruch and Marshall (1966, 1969) analyzed large-scale heat flow changes across the boundary between Alpha Ridge and northwest Canada Basin (now Nautilus Basin). They correctly inferred the existence of thick volcanic basement beneath Alpha Ridge, as was later shown by other researchers analyzing seismic or potential field data sets (e.g., Funck et al., 2011; Jackson et al., 1986; Kusznir \& Gaina, 2011; Oakey \& Saltus, 2016). In the Lachenbruch and Marshall (1969) interpretation, the increased heat flow in Nautilus Basin (Figure 12) is an edge effect associated with presence of relatively lower thermal conductivity volcanic rocks beneath Alpha Ridge.

The T-3 data set was completed a few years after the publication of Lachenbruch and Marshall (1969), and no comprehensive interpretation of the variability in heat flow has ever been undertaken. Figure 13 depicts data within $\sim 20 \mathrm{~km}$ of a 1,600-km-long profile through the densest concentration of T-3 heat flow data on Alpha Ridge, in Nautilus Basin, and onto Mendeleev Ridge. Heat flow values vary from $~ 35$ to 85 $\mathrm{mW} / \mathrm{m}^{2}$. Even closely spaced measurements along the profile do not suggest clear correlations with local bathymetric features or known variations in sediment thickness (e.g., inferred to be thin on the ridges and a maximum of $2 \mathrm{~km}$ thick in Nautilus Basin). Figure 13 reveals relative increases in heat flow in some subbasins within Alpha and Mendeleev Ridges and also captures some of the higher heat flow discussed for Nautilus Basin in section 5.2.4 (Figure 12) and analyzed by Lachenbruch and Marshall (1969). Seismic data (e.g., Mosher \& Hutchinson, 2019) have imaged considerable complexity at the transition from Nautilus Basin to Alpha Ridge, but the observed heat flow pattern is consistent with lower bulk thermal conductivity and/or lower thermal gradients beneath ridges than beneath adjacent basins. Note that Figure 13 also does not reveal a clear pattern of heat flow variations across Alpha Ridge seafloor where subbottom profiling data imaged deformed hemipelagic drape (Boggild et al., 2018) that has been interpreted as a possible impact structure (Kristoffersen et al., 2009). The location of this feature is indicated by the black outline in Figure 7.

To explore large-scale heat flow variability in the Amerasian Basin, we used $\sim 1200 \mathrm{~km}$ of a published crustal cross-section interpretation (Oakey \& Saltus, 2016) trending approximately south-to-north from Canada Basin across southern Alpha Ridge (Nautilus Spur) and thence across Alpha Ridge (position shown in Figure 7). The crustal units portrayed by Oakey and Saltus (2016) based on analysis of potential field data were digitized to build a geometry for use in Matlab's PDEsolver, which automatically generates and refines a finite element (FE) mesh. We assigned nominal thermal conductivities to the surface sediment, Alpha Ridge volcaniclastics, crustal basalts (HALIP beneath Alpha Ridge and oceanic beneath Canada Basin), and the thick lower crust under Alpha Ridge (Table 4). The assigned bulk thermal conductivity in the 


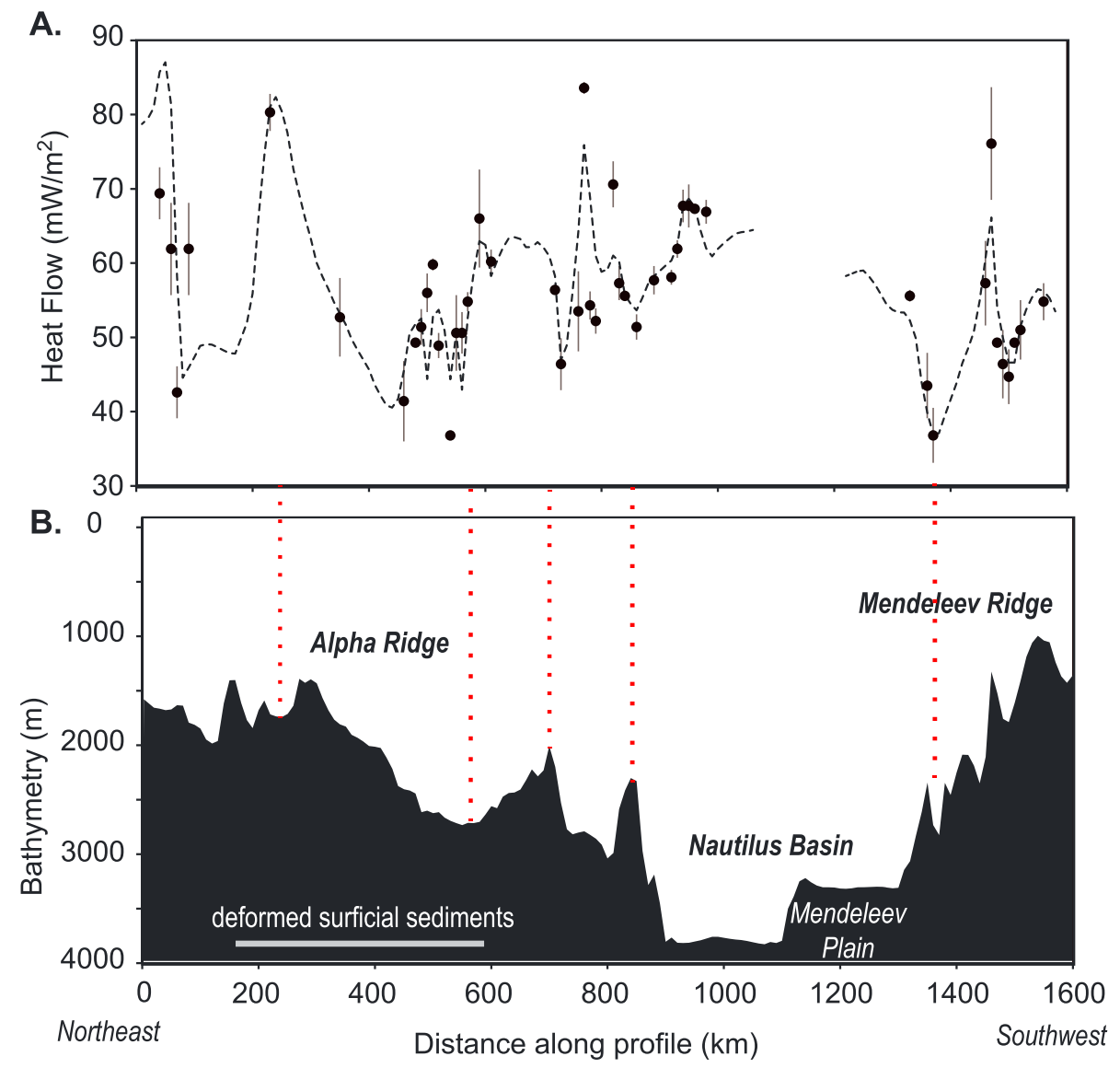

Figure 13. (a) Alpha Ridge, Nautilus Basin, and Mendeleev Ridge measured T-3 heat flow measurements (points) with uncertainties and heat flow along a transect through the gridded data (dashed line) through densely surveyed locations. Profile location and gridded data shown in Figure 7. (b) IBCAO bathymetry (Jakobsson et al., 2012) along the transect. The deformed surficial sediments mapped by Boggild et al. (2018) on Alpha Ridge are in the same location as a postulated extraterrestrial impact structure (Kristoffersen et al., 2009). In the classification of Jakobsson et al. (2003), Nautilus Basin physiographic province includes Mendeleev Plain, which constitutes the southern part of that basin.

upper $30 \mathrm{~km}$ beneath Alpha Ridge $\left(\sim 2 \mathrm{~W} \mathrm{~m}^{-1} \mathrm{~K}^{-1}\right)$ is $\sim 30 \%$ lower than that beneath Canada Basin $(\sim 2.6 \mathrm{~W} \mathrm{~m}$ ${ }^{-1} \mathrm{~K}^{-1}$ ), although the thermal conductivity difference is not as dramatic (100\% difference) as that adopted in the analytical model of Lachenbruch and Marshall (1969).

We solved the steady state heat conduction equation assuming constant temperature at the seafloor $\left(0^{\circ} \mathrm{C}\right)$ and $35-\mathrm{km}$ depth $\left(700^{\circ} \mathrm{C}\right)$ and no flux boundaries on either side of the model. To produce the most generic

Table 4

Thermal Conductivity Values Assigned to the Crustal Units Shown in Figure 14a for the Finite Element Steady State Heat Conduction Model

\begin{tabular}{lc}
\hline Crustal unit & $\begin{array}{c}\text { Thermal conductivity } \\
\left(\mathrm{W} \mathrm{m}^{-1} \mathrm{~K}^{-1}\right)\end{array}$ \\
\hline Surface sediments & 1.0 \\
Alpha Ridge volcaniclastics & 1.7 \\
Alpha ridge HALIP rocks and Canada Basin & 2.0 \\
oceanic crust & \\
Alpha Ridge continental-affinity lower crust & 2.5 \\
Canada Basin lower crust & 2.5 \\
Upper mantle & 3.1 \\
\hline
\end{tabular}
solution and one not dependent on interpretations about the role of continental material in the HALIP magmatism, no crustal radiogenic heat sources were included. The steady state temperature structure (Figure 14a) and calculated vertical heat flow (Figure 14b) show that shallow relief features (ridges) have lower thermal gradients and heat flow, while basin features close to bathymetric highs have more elevated gradients and heat flow. The pattern emerges both at the local to regional scale ( $<100 \mathrm{~km}$; transition between Nautilus Spur and Canada Basin) and at the large scale (Alpha Ridge versus Canada Basin).

At the local to regional scale, researchers have long noted the impact of bathymetric variations on conductive heat flow. A modern summary of these issues is given by Fisher and Harris (2010), who demonstrate that buried basement highs can be associated with locally elevated 

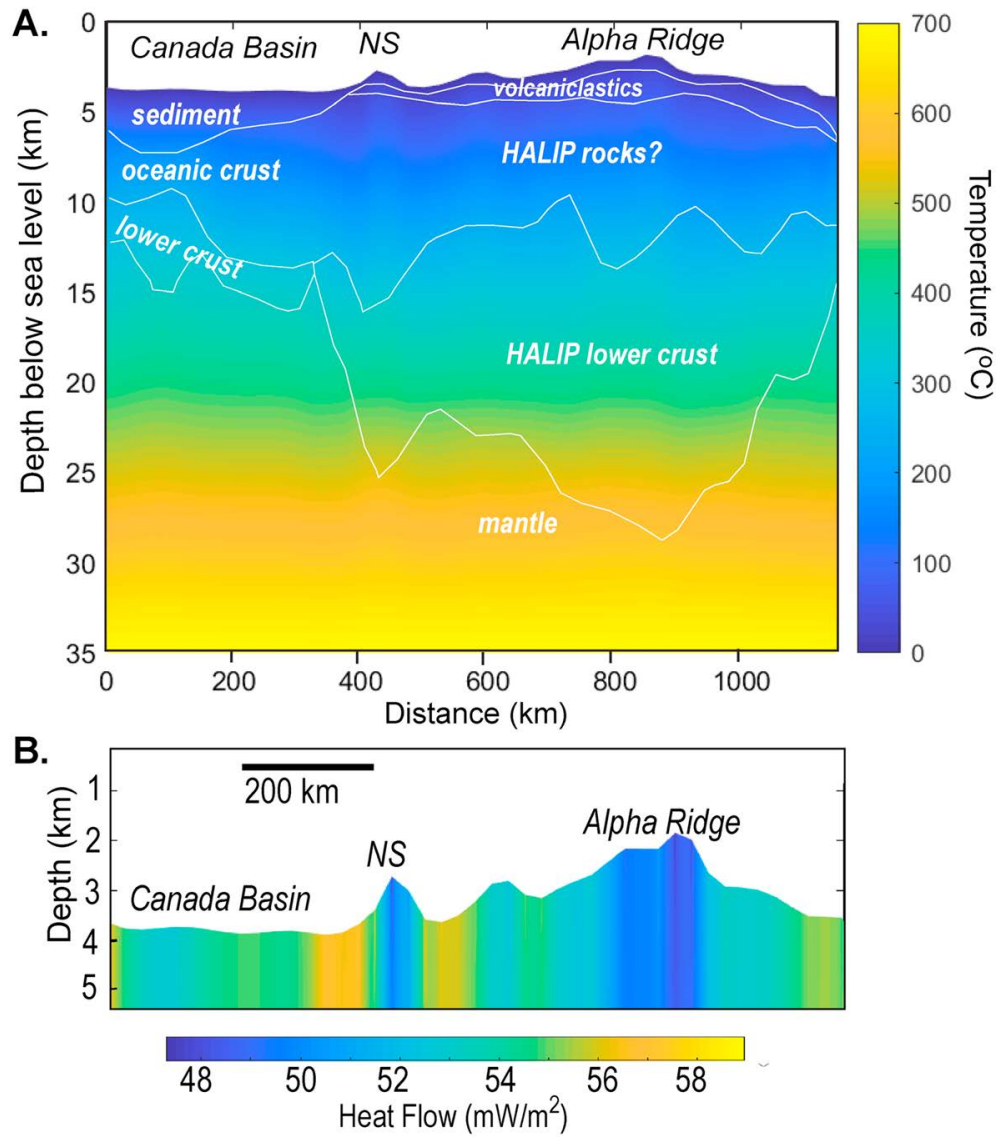

Figure 14. (a) Steady-state temperatures produced by a finite element (FE) model that includes the crustal units depicted here, which were digitized from a Canada Basin to Alpha Ridge cross section analyzed by Oakey and Saltus (2016). NS denotes Nautilus Spur. The location of the profile is shown in Figure 7, and the assigned thermal conductivities are given in Table 4. (b) Vertical heat flow calculated from the FE solution to the heat conduction equation for this combination of bathymetry, crustal unit geometry, and thermal conductivities.

conductive heat flow due to heat refraction effects. Basement highs that rise above surrounding seafloor can be loci of either net recharge (manifests as lower conductive heat flow) or discharge (produces elevated conductive heat flow). The modeled conductive heat flow pattern in Figure 14 emerges without the inclusion of advective heat transfer via seawater circulation in the sediments or the shallow crust. Fluid circulation through sediments and shallow crust could increase or lower predicted conductive heat flow depending on the distribution of recharge and discharge sites and the role of local sediments and basement in facilitating such circulation. The inference that circulation of fluids through sediments and shallow basement affects local heat flow patterns is consistent with the analyses in section 5.2, which highlight fluid circulation through faults and fractured crust as a factor in enhancing heat flow variability recorded by the T-3 data set.

The numerical model (Figure 14b) also produces a large-scale pattern of conductive heat flow variations between Alpha Ridge $\left(48-50 \mathrm{~mW} / \mathrm{m}^{2}\right.$ at the crest) and Canada Basin $\left(53-55 \mathrm{~mW} / \mathrm{m}^{2}\right)$. The modeled heat flow for these larger features is affected by the deeper thermal conductivity structure as well as their average bathymetry. The juxtaposition of higher and lower heat flow is similar to, but smaller than, the large-scale edge effect calculated by Lachenbruch and Marshall (1969) based on an analytical model for the Nautilus Basin to Alpha Ridge transition. In the T-3 data, the average heat flow values (excluding uncertainties) observed for Canada Basin and Alpha Ridge are statistically indistinguishable (Table 2), which implies that the model may predict heat flow values too low for Alpha Ridge. The measured heat flow at Alpha Ridge may reflect superposed advective heating related to the expulsion of warm fluids through fractured basement that is covered by only thin sediments. A core recovered by the USGS in 2010 on a seamount near 
Acknowledgments

B.V. Marshall of the U.S. Geological Survey (USGS) was critical to the T-3 heat flow studies and would have been included as a coauthor on this work if he were not deceased. The original $\mathrm{T}-3$ heat flow data acquisition program was supported by the USGS and by the Naval Arctic Research Laboratory of the Office of Naval Research. Over the decade of USGS research on T-3 Ice Island, numerous researchers and technical staff, including B.V. Marshall, P. Twichell, D. Scoboria, J. Tailleur, B. Tailleur, and others, spent months on the island and endured difficult and sometimes dangerous conditions to acquire this data set alongside colleagues from other institutions. Outstanding support from the USGS Menlo Park office, transportation and logistics assistance from other U.S. federal government agencies, Arctic expertise supplied by native Alaskan communities, and collaboration with Lamont researchers made this research program possible. B. Lachenbruch and L. Lawver revived interest in this data set in 2016, and they, along with D. Darby and J. K. Hall, provided ancillary information on T-3 studies. B. Clarke and M. Arsenault assisted with initial data digitization. We thank M.

Jakobsson, R. Saltus, and G. Oakey for providing critical shapefiles and other data and R. Jackson and S. Mukasa for clarification on unpublished information. Reviews by J. Hopper, P. Hart, and W. Jokat improved the manuscript, and V. Atnipp Cross and A. Babb were instrumental in completion of data releases. The USGS's

Coastal/Marine Hazards and Resources Program supported C.R. and D.H. between 2016 and 2019, and C.R. used office space provided by the Earth Resources Laboratory at the Massachusetts Institute of Technology during completion of this work. Data in Figure 11 were provided by the U.S. Extended Continental Shelf (ECS) Project. The opinions, findings, and conclusions stated herein are those of the authors and the U.S. Geological Survey, but do not necessarily reflect those of the U.S. ECS Project. Any use of trade, firm, or product name is for descriptive purposes only and does not imply endorsement by the U.S. Government. Digital data, metadata, and supporting plots for T-3 heat flow, navigation, and radiogenic heat content, along with Lamont gravity and magnetics data, are available from Ruppel et al. (2019), and the original $\mathrm{T}$ 3 expedition report with explanatory metadata can be downloaded from Lachenbruch et al. (2019).
Alpha Ridge showed orange staining interpreted as a by-product of the circulation of warm fluids through the sediments (D. Mosher, personal communications, June 2019).

The FE model was also run for conditions of prescribed flux at 35-km depth, and the calculated solution showed the same pattern of elevated and depressed seafloor heat flow. The objective of the FE model was not to produce an exact match to observed heat flow patterns. However, even the simple result shown here demonstrates that heat flow variation of more than $10 \%$ can be obtained by adopting simple assumptions and basic constraints on the configuration and thermal conductivities of crustal units. More refined models that include radiogenic heating, advective flux, and better constraints on thermal conductivity and other thermal characteristics specific to the thick volcanic sequences beneath AMR (Oakey \& Saltus, 2016) and thinner continental and/or oceanic crust beneath parts of Nautilus Basin and northern Canada Basin would likely account for even more of the observed heat flow variability in the T-3 data set.

\section{Conclusions}

The T-3 marine heat flow data, as documented in this study, in the data report of Lachenbruch et al. (2019), and in the associated data release (Ruppel et al., 2019), provide a rich and previously unavailable geophysical data set for the High Arctic. The T-3 data also greatly increase the number of known Arctic Ocean heat flow measurements and render this ocean basin among the most densely sampled for its thermal characteristics. Since the data were acquired from a drifting ice island, instead of an oceanographic vessel, researchers had control only over the frequency, but not the location, of the measurements. The resulting uneven spatial distribution of heat flow points yields dense clusters of measurements in some areas (e.g., northern Nautilus Basin, much of Alpha Ridge), but critical gaps in others. Even today, major Amerasian Basin heat flow data gaps remain in much of Canada Basin and on Chukchi Plateau and Northwind Ridge, as well as on the western side of Mendeleev Ridge.

Some of the variability in the T-3 data set may arise due to the juxtaposition of HALIP-related magmatic sequences beneath features like AMR with oceanic crust and possibly continental crustal fragments beneath parts of Nautilus and Canada basins. As noted by Lachenbruch and Marshall (1969) and shown with the simple conductive thermal model formulated here, crustal-scale thermal conductivity variations associated with thickened crust beneath features like Alpha Ridge can produce heat flow variations between the ridge and adjacent basins. At a smaller scale, the thermal model from section 5.3 shows that local bathymetric highs can be associated with decreased heat flow and juxtaposed with higher heat flow intraridge basins even when no advective flux (e.g., fluid circulation through faulted crust) is included. Superposed on this scale of ridge-basin variability are lateral changes in lithology, sediment thickness, and radiogenic heat continent and probable seawater circulation through faults.

\section{References}

Amato, J. M., Toro, J., Akinin, V. V., \& Hampton, B. A. (2017). Tectonic evolution of the Mesozoic South Anyui suture zone, eastern Russia: A critical component of paleogeographic reconstructions of the Arctic region: REPLY. Geosphere, 13(5), 1769-1773. https://doi.org/ 10.1130/GES01541.1

Boggild, K., Mosher, D. C., Gebhardt, C., Jakobsson, M., Mayer, L. A., Hogan, K., \& Dove, D. (2018). Surficial geology of the Amerasian Basin from subbottom profiler data, Open File Report 8465. Ottawa, Canada: Geological Survey of Canada.

Brumley, K., Miller, E. L., Konstantinou, A., Grove, M., Meisling, K. E., \& Mayer, L. A. (2015). Geologic history of the Chukchi Borderland, Arctic Ocean. Geosphere, 11(1), 76-92. https://doi.org/10.1130/GES01044.1

Bruvoll, V., Kristoffersen, Y., Coakley, B. J., \& Hopper, J. R. (2010). Hemipelagic deposits on the Mendeleev and northwestern Alpha submarine Ridges in the Arctic Ocean: Acoustic stratigraphy, depositional environment and an inter-ridge correlation calibrated by the ACEX results. Marine Geophysical Researches, 31(3), 149-171. https://doi.org/10.1007/s11001-010-9094-9

Bruvoll, V., Kristoffersen, Y., Coakley, B. J., Hopper, J. R., Planke, S., \& Kandilarov, A. (2012). The nature of the acoustic basement on Mendeleev and northwestern Alpha ridges, Arctic Ocean. Tectonophysics, 514-517, 123-145. https://doi.org/10.1016/j.tecto.2011.10.015

Bunker, C. M., \& Bush, C. A. (1966). Uranium, thorium, and radium analyses by gamma-ray spectrometry (0.184-0.352 million electron volts), U.S. Geological Survey Professional Paper 550-B, pp. B176-181.

Bunker, C. M., \& Bush, C. A. (1967). A comparison of potassium analyses by gamma-ray spectrometry and other techniques, U.S. Geological Survey Professional Paper 575-B, pp. B164-169.

Butsenko, V. V., Firsov, Y. G., Gusev, E. A., Kaminsky, V. D., Kashubin, S. P., Piskarev, A. L., \& Poselov, V. A. (2019). Mendeleev and Alpha Ridges. In A. Piskarev, V. A. Poselov, \& V. Kaminsky (Eds.), Geologic structures of the Arctic Basin (pp. 239-268). Basel, Switzerland: Springer International.

Chian, D., Jackson, H. R., Hutchinson, D. R., Shimeld, J. W., Oakey, G. N., Lebedeva-Ivanova, N., et al. (2016). Distribution of crustal types in Canada Basin, Arctic Ocean. Tectonophysics, 691, 8-30. https://doi.org/10.1016/j.tecto.2016.01.038

Clark, D. L. (1971). Arctic Ocean ice cover and its late Cenozoic history. GSA Bulletin, 82(12), 3313-3324. https://doi.org/10.1130/00167606(1971)82[3313:AOICAI]2.0.CO;2 
Clark, D. L., Whitman, R. R., Morgan, K. A., \& Mackey, S. D. (1980). Stratigraphy and glacial-marine sediments of the Amerasian Basin, central Arctic Ocean, Special Paper 181 (p. 57). Boulder, CO: Geological Society of America.

Coakley, B., Hopper, J., \& Kristoffersen, Y. (2005). Migrated MCS data from HOTRAX, HLY0503, Healy-Oden Trans-Arctic Expedition. In G. Christeson, T. Shipley, L. Gahagan, K. Johnson, \& M. Davis (Eds.), Academic Seismic Portal (ASP) of University of Texas Institute for Geophysics. URL. http://www-udc.ig.utexas.edu/sdc/

Corfu, F., Polteau, S., Planke, S., Faleide, J. I., Svensen, H., Zayoncheck, A., \& Stolbov, N. (2013). U-Pb geochronology of Cretaceous magmatism on Svalbard and Franz Josef Land, Barents Sea Large Igneous Province. Geological Magazine, 150(6), 1127-1135. https://doi. org/10.1017/S0016756813000162

Crary, A. P., Cotell, R. D., \& Sexton, T. F. (1952). Preliminary report on scientific work on "Fletcher's Ice Island,” T3. Arctic, 5(4), 211-223. https://doi.org/10.14430/arctic3913

Darby, D. A., Naidu, A. S., Mowatt, T. C., \& Jones, G. (1989). Sediment composition and sedimentary processes in the Arctic Ocean. In Y. Herman (Ed.), The Arctic Seas: Climatology, Oceanography, Geology, and Biology (pp. 657-720). Boston, MA: Springer US. https://doi. org/10.1007/978-1-4613-0677-1_24

De Laurier, J. (1978). The Alpha Ridge is not a spreading centre. In J. F. Sweeney (Ed.), Arctic Geophysical Review (Vol. 45, pp. 87-90). Ottawa, Canada: Earth Physics Branch.

Dietz, R. S., \& Shumway, G. (1961). Arctic Basin geomorphology. Geological Society of America Bulletin, 72(9), 1319-1329. https://doi.org/ 10.1130/0016-7606(1961)72[1319:abg]2.0.co;2

Dockman, D. M., Pearson, D. G., Heaman, L. M., Gibson, S. A., \& Sarkar, C. (2018). Timing and origin of magmatism in the Sverdrup Basin, Northern Canada-Implications for lithospheric evolution in the High Arctic Large Igneous Province (HALIP). Tectonophysics, 742-743, 50-65. https://doi.org/10.1016/j.tecto.2018.05.010

Døssing, A., Jackson, H. R., Matzka, J., Einarsson, I., Rasmussen, T. M., Olesen, A. V., \& Brozena, J. M. (2013). On the origin of the Amerasia Basin and the High Arctic Large Igneous Province-Results of new aeromagnetic data. Earth and Planetary Science Letters, 363, 219-230. https://doi.org/10.1016/j.epsl.2012.12.013

Dove, D., Coakley, B., Hopper, J., Kristoffersen, Y., \& H. L. Y. G. Team* (2010). Bathymetry, controlled source seismic and gravity observations of the Mendeleev ridge: Implications for ridge structure, origin, and regional tectonics. Geophysical Journal International, 183(2), 481-502. https://doi.org/10.1111/j.1365-246X.2010.04746.X

Estrada, S., Damaske, D., Henjes-Kunst, F., Schreckenberger, B., Oakey, G. N., Piepjohn, K., et al. (2016). Multistage Cretaceous magmatism in the northern coastal region of Ellesmere Island and its relation to the formation of Alpha Ridge-Evidence from aeromagnetic, geochemical and geochronologic data. Norwegian Journal of Geology, 96(2), 65-95. https://doi.org/10.17850/njg96-2-03

Evangelatos, J., Funck, T., \& Mosher, D. C. (2017). The sedimentary and crustal velocity structure of Makarov Basin and adjacent Alpha Ridge. Tectonophysics, 696-697, 99-114. https://doi.org/10.1016/j.tecto.2016.12.026

Fisher, A. T., \& Harris, R. N. (2010). Using seafloor heat flow as a tracer to map subseafloor fluid flow in the ocean crust. Geofluids, 10(1-2), 142-160. https://doi.org/10.1111/j.1468-8123.2009.00274.x

Forsyth, D. A., Morel-A-L'Huissier, P., Asudeh, I., \& Green, A. G. (1986). Alpha Ridge and iceland-Products of the same plume? Journal of Geodynamics, 6(1-4), 197-214. https://doi.org/10.1016/0264-3707(86)90039-6

Funck, T., Jackson, H. R., \& Shimeld, J. (2011). The crustal structure of the Alpha Ridge at the transition to the Canadian Polar Margin: Results from a seismic refraction experiment. Journal of Geophysical Research, 116, B12101. https://doi.org/10.1029/ 2011JB008411

Gaina, C., Medvedev, S., Torsvik, T. H., Koulakov, I., \& Werner, S. C. (2014). 4D Arctic: A glimpse into the structure and evolution of the Arctic in the light of new geophysical maps, plate tectonics and tomographic models. Surveys in Geophysics, 35(5), 1095-1122. https:// doi.org/10.1007/s10712-013-9254-y

Hall, J. K. (1970). Arctic Ocean geophysical studies: The Alpha Cordillera and the Mendeleev Ridge, Report for Office of Naval Research, CU2-70, Lamont-Doherty Geological Observatory of Columbia University, http://www.dtic.mil/dtic/tr/fulltext/u2/715656.pdf

Hall, J. K. (2010). Polar navigation for research: Then and now, Navigation News (pp. 13-16). United Kingdom: Royal Institution of Navigation.

Hunkins, K., \& Tiemann, W. (1977). Geophysical data summary for Fletcher's Ice Island (T-3), 1962-1974, Technical Report, LamontDoherty Survey of the World Ocean Rep. CU-1-77, 219 pp, Lamont-Doherty Geological Observatory,

Hyndman, R. D., Davis, E. E., \& Wright, J. A. (1979). The measurement of marine geothermal heat flow by a multipenetration probe with digital acoustic telemetry and in situ thermal conductivity. Marine Geophysical Researches, 4(2), 181-205. https://doi.org/10.1007/ BF00286404

IHFC (2012). The global heat flow database of the International Heat Flow Commission (IHFC), University of North Dakota. https:// engineering.und.edu/research/global-heat-flow-database/

Ilhan, I., \& Coakley, B. J. (2018). Meso-Cenozoic evolution of the southwestern Chukchi Borderland, Arctic Ocean. Marine and Petroleum Geology, 95, 100-109. https://doi.org/10.1016/j.marpetgeo.2018.04.014

Jackson, H. R., Chian, D., \& Shimeld, J. (2018). Continental affinities of the Alpha Mendeleev Ridge, paper presented at International Conference on Arctic Margins VIII, Stockholm, Sweden, June 11-14, 2018, https://icamviii.geo.su.se/en/program/Marine\%20G\&G_ jackson.et.al.pdf

Jackson, H. R., Forsyth, D. A., \& Johnson, G. L. (1986). Oceanic affinities of the Alpha Ridge, Arctic Ocean. Marine Geology, 73(3-4), 237-261. https://doi.org/10.1016/0025-3227(86)90017-4

Jakobsson, M., Grantz, A., Kristoffersen, Y., \& Macnab, R. (2003). Physiographic provinces of the Arctic Ocean seafloor. Geological Society of America Bulletin, 115(12), 1443-1455. https://doi.org/10.1130/B25216.1

Jakobsson, M., Mayer, L., Coakley, B., Dowdeswell, J. A., Forbes, S., Fridman, B., et al. (2012). The International Bathymetric Chart of the Arctic Ocean (IBCAO) version 3.0. Geophysical Research Letters, 39, L12609. https://doi.org/10.1029/2012GL052219

Jokat, W. (2003). Seismic investigations along the western sector of Alpha Ridge, central Arctic Ocean. Geophysical Journal International, 152(1), 185-201. https://doi.org/10.1046/j.1365-246X.2003.01839.x

Jokat, W. (Ed) (2009). The expedition of the research vessel "Polarstern" to the Arctic in 2008 (ARK-XXIII/3), Reports on Polar and Marine Research Rep. 597, 226 pp. http://hdl.handle.net/10013/epic.33317

Jokat, W., Ickrath, M., \& O'Connor, J. (2013). Seismic transect across the Lomonosov and Mendeleev Ridges: Constraints on the geological evolution of the Amerasia Basin, Arctic Ocean. Geophysical Research Letters, 40, 5047-5051. https://doi.org/10.1002/grl.50975

Kashubin, S. N., Petrov, O. V., Artemieva, I. M., Morozov, A. F., Vyatkina, D. V., Golysheva, Y. S., et al. (2018). Crustal structure of the Mendeleev Rise and the Chukchi Plateau (Arctic Ocean) along the Russian wide-angle and multichannel seismic reflection experiment “Arctic-2012”. Journal of Geodynamics, 119, 107-122. https://doi.org/10.1016/j.jog.2018.03.006 
Kristoffersen, Y., Hall, J. K., Hunkins, K., Ardai, J., Coakley, B., Hopper, J. R., \& Team, H. S. (2009). Extensive local seabed disturbance, erosion and mass wasting on Alpha Ridge, central Arctic Ocean: Possible evidence for an extra-terrestrial impact? Norwegian Journal of Geology, 88, 313-320

Kusznir, N. J., \& Gaina, C. (2011). Is Alpha Ridge oceanic or continental crust? Constraints from gravity and magnetic potential field data, paper presented at 3P Arctic, The Polar Petroleum Potential Conference \& Exhibition, Nova Scotia, Canada, August 30-September 2, http://www.searchanddiscovery.com/abstracts/html/2011/3Parctic/abstracts/kusznir02.htm

Lachenbruch, A. H., \& Marshall, B. V. (1966). Heat flow through the Arctic Ocean floor: The Canada Basin-Alpha Rise Boundary. Journal of Geophysical Research, 71(4), 1223-1248. https://doi.org/10.1029/JZ071i004p01223

Lachenbruch, A. H., \& Marshall, B. V. (1969). Heat flow in the Arctic. Arctic, 22(3), 300-311. https://doi.org/10.14430/arctic3221

Lachenbruch, A. H., Marshall, B. V., \& Ruppel, C. D. (2019). Post-expedition report for USGS T-3 heat flow measurements in the High Arctic Ocean, U.S. Geological Survey data release, doi:https://doi.org/10.5066/P91XQ3IS

Langseth, M. G., Lachenbruch, A. H., \& Marshall, B. V. (1990). Geothermal observations in the Arctic region. In A. Grantz, L. Johnson, \& J. F. Sweeney (Eds.), The Arctic Ocean Region (pp. 133-152). Boulder, CO: Geological Society of America. https://doi.org/10.1130/DNAGGNA-L.133

Lawver, L. A., \& Müller, R. D. (1994). Iceland hotspot track. Geology, 22(4), 311-314. https://doi.org/10.1130/0091-7613(1994)022<0311: IHT $>2.3 . \mathrm{CO} ; 2$

Lebedeva-Ivanova, N. N., Zamansky, Y. Y., Langinen, A. E., \& Sorokin, M. Y. (2006). Seismic profiling across the Mendeleev Ridge at $82^{\circ} \mathrm{N}$ : Evidence of continental crust. Geophysical Journal International, 165(2), 527-544. https://doi.org/10.1111/j.1365246X.2006.02859.X

Lister, C. R. B. (1979). The pulse-probe method of conductivity measurement. Geophysical Journal International, 57(2), 451-461. https:// doi.org/10.1111/j.1365-246X.1979.tb04788.x

Louden, K. E., Leger, G., \& Hamilton, N. (1990). Marine heat flow observations on the Canadian Arctic continental shelf and slope. Marine Geology, 93, 267-288. https://doi.org/10.1016/0025-3227(90)90087-Z

Lubimova, E. A., Polyak, B. G., Smirnov, Y. B., Kutas, R. I., Firsov, F. V., Sergienko, S. I., \& Luisova, L. N. (1973). Heat flow on the USSR Territory: Catalogue of data, 1964-1972, Soviet Geophysics. Moscow: Committee of the Academy of Sciences of the USSR.

Morozov, A. F., Petrov, O. V., Shokalsky, S. P., Kashubin, S. N., Kremenetsky, A. A., Shkatov, M. Y., et al. (2013). New geological data are confirming continental origin of the central Arctic rises. Regional geology and metallogeny, 53, 34-55.

Mosher, D. C., \& Hutchinson, D. R. (2019). Canada Basin. In A. Piskarev, V. A. Poselov, \& V. Kaminsky (Eds.), Geologic Structures of the Arctic Basin (pp. 295-325). Basel, Switzerland: Springer International.

Mosher, D. C., Shimeld, J., Hutchinson, D., Chian, D., Lebedova-Ivanova, N., \& Jackson, R. (2012). Canada Basin Revealed, paper presented at OTC Arctic Technology Conference, Offshore Technology Conference, Houston, Texas, USA, 12/3/2012, https://www.onepetro.org/conference-paper/OTC-23797-MS

Mukasa, S. B., Mayer, L. A., Aviado, K., Bryce, J., Andronikov, A., Brumley, K., et al. (2015). Alpha/Mendeleev Ridge and Chukchi borderland ${ }^{40} \mathrm{Ar} /{ }^{39} \mathrm{Ar}$ geochronology and geochemistry: Character of the first submarine intraplate lavas recovered from the Arctic Ocean, paper presented at European Geophysical Union General Assembly, Vienna, Austria, http://meetingorganizer.copernicus.org/ EGU2015/EGU2015-8291-2.pdf

Nejbert, K., Krajewski, K. P., Dubinska, E., \& Pécskay, Z. (2011). Dolerites of Svalbard, north-west Barents Sea Shelf: Age, tectonic setting and significance for geotectonic interpretation of the High-Arctic Large Igneous Province AU - Nejbert, Krzysztof. Polar Research, 30(1), 7306. https://doi.org/10.3402/polar.v30i0.7306

Nikishin, A. M., Malyshev, N. A., \& Petrov, E. I. (2015). Geological structure and history of the Arctic Ocean (p. 88). Netherlands: EAGE Publications. https://doi.org/10.3997/9789462821880

Nikishin, A. M., Petrov, E. I., Malyshev, N. A., \& Ershova, V. P. (2017). Rift systems of the Russian eastern Arctic shelf and Arctic deep water basins: Link between geological history and geodynamics. Geodynamics and Tectonophysics, 8(1), 11-43. https://doi.org/10.5800/GT2017-8-1-0231

Oakey, G. N., \& Saltus, R. W. (2016). Geophysical analysis of the Alpha-Mendeleev ridge complex: Characterization of the High Arctic Large Igneous Province. Tectonophysics, 691, 65-84. https://doi.org/10.1016/j.tecto.2016.08.005

O'Regan, M., Preto, P., Stranne, C., Jakobsson, M., \& Koshurnikov, A. (2016). Surface heat flow measurements from the East Siberian continental slope and southern Lomonosov Ridge, Arctic Ocean. Geochemistry, Geophysics, Geosystems, 17, 1608-1622. https://doi.org/ 10.1002/2016GC006284

Parsons, B., \& Sclater, J. G. (1977). An analysis of the variation of ocean floor bathymetry and heat flow with age. Journal of Geophysical Research, 82(5), 803-827. https://doi.org/10.1029/JB082i005p00803

Paterson, W. S. B., \& Law, L. K. (1966). Additional heat flow measurements in the area of Mould Bay, Arctic Canada. Canadian Journal of Earth Sciences, 3(2), 237-246. https://doi.org/10.1139/e66-019

Petrov, O., Morozov, A., Shokalsky, S., Kashubin, S., Artemieva, I. M., Sobolev, N., et al. (2016). Crustal structure and tectonic model of the Arctic region. Earth-Science Reviews, 154, 29-71. https://doi.org/10.1016/j.earscirev.2015.11.013

Polyak, L., Darby, D. A., Bischof, J. F., \& Jakobsson, M. (2017). Stratigraphic constraints on late Pleistocene glacial erosion and deglaciation of the Chukchi margin, Arctic Ocean. Quaternary Research, 67(2), 234-245. https://doi.org/10.1016/j.yqres.2006.08.001

Pribnow, D. F. C., Konishita, M., \& Stein, C. A. (2000). Thermal data collection and heat flow recalculations for ODP Legs 101-180, Report 0120432, Institute for Joint Geoscientific Research, Hannover, Germany, http://www-odp.tamu.edu/publications/heatflow/.

Ratcliffe, E. H. (1960). The thermal conductivities of ocean sediments. Journal of Geophysical Research, 65(5), 1535-1541. https://doi.org/ 10.1029/JZ065i005p01535

Ruppel, C., Hutchinson, D. R., Lachenbruch, A. H., \& Hall, J. K. (2019). Thermal data and navigation for T-3 (Fletcher's) ice island Arctic Ocean heat flow studies, 1963-73, U.S. Geological Survey data release, doi:https://doi.org/10.5066/P97EPU2F

Ruppel, C., von Herzen, R. P., \& Bonneville, A. (1995). Heat flux through an old ( $175 \mathrm{Ma})$ passive margin: Offshore southeastern United States. Journal of Geophysical Research, 100(B10), 20,037-20,057. https://doi.org/10.1029/95JB01860

Saumur, B. M., Dewing, K., \& Williamson, M. C. (2016). Architecture of the Canadian portion of the High Arctic Large Igneous Province and implications for magmatic Ni-Cu potential. Canadian Journal of Earth Sciences, 53(5), 528-542. https://doi.org/10.1139/cjes-20150220

Sclater, J. G., Corry, C. E., \& Vacquier, V. (1969). In situ measurement of the thermal conductivity of ocean-floor sediments. Journal of Geophysical Research, 74(4), 1070-1081. https://doi.org/10.1029/JB074i004p01070

Sergeev, S. A., Petrov, O., Morozov, A. F., Kremenetsky, A. A., Gusev, E. A., Shevchenko, S. S., \& Rodionov, N. (2013). Volcanic rocks of the Mendeleev Ridge (Arctic Ocean)_Evidences for existence of the large igneous provinces within Arctic region: On the data of the High 
Arctic Russian Expedition “Arctic-2012”, paper presented at EGU General Assembly, https://meetingorganizer.copernicus.org/ EGU2013/EGU2013-13484.pdf

Shephard, G. E., Müller, R. D., \& Seton, M. (2013). The tectonic evolution of the Arctic since Pangea breakup: Integrating constraints from surface geology and geophysics with mantle structure. Earth-Science Reviews, 124, 148-183. https://doi.org/10.1016/j. earscirev.2013.05.012

Shephard, G. E., Wiers, S., Bazhenova, E., Pérez, L. F., Mejía, L. M., Johansson, C., et al. (2018). A North Pole thermal anomaly? Evidence from new and existing heat flow measurements from the central Arctic Ocean. Journal of Geodynamics, 118, 166-181. https://doi.org/ 10.1016/j.jog.2018.01.017

Shimeld, J., Li, Q., Chian, D., Lebedeva-Ivanova, N., Jackson, R., Mosher, D., \& Hutchinson, D. (2016). Seismic velocities within the sedimentary succession of the Canada Basin and southern Alpha-Mendeleev Ridge, Arctic Ocean: Evidence for accelerated porosity reduction? Geophysical Journal International, 204(1), 1-20. https://doi.org/10.1093/gji/ggv416

Stein, C. A., \& Stein, S. (1992). A model for the global variation in oceanic depth and heat flow with lithospheric age. Nature, 359(6391), 123-129. https://doi.org/10.1038/359123a0

Stein, C. A., \& Stein, S. (1993). Constraints on Pacific midplate swells from global depth-age and heat flow-age models. In M. S. Pringle, W W. Sager, W. V. Sliter, \& S. Stein (Eds.), The Mesozoic Pacific: Geology, Tectonics, and Volcanism. https://doi.org/10.1029/GM077p0053 Stein, C. A., \& Von Herzen, R. P. (2007). Potential effects of hydrothermal circulation and magmatism on heatflow at hotspot swells. In G. R. Foulger, \& D. M. Jurdy (Eds.), Plates, Plumes, and Planetary Processes (pp. 261-274). Boulder, CO: Geological Society of America. https://doi.org/10.1130/2007.2430(13)

Taylor, A., Judge, A., \& Allen, V. (1986). Terrestrial heat flow from project CESAR, Alpha Ridge, Arctic Ocean. Journal of Geodynamics, 6(1-4), 137-176. https://doi.org/10.1016/0264-3707(86)90037-2

Tegner, C., Storey, M., Holm, P. M., Thorarinsson, S. B., Zhao, X., Lo, C. H., \& Knudsen, M. F. (2011). Magmatism and Eurekan deformation in the High Arctic Large Igneous Province: ${ }^{40} \mathrm{Ar}-{ }^{39} \mathrm{Ar}$ age of Kap Washington Group volcanics, North Greenland. Earth and Planetary Science Letters, 303(3-4), 203-214. https://doi.org/10.1016/j.epsl.2010.12.047

University of Wisconsin, Dept. of Geoscience (2015). Archive of information about the Ice Island T3 piston core collection, National Center for Environmental Information, doi:https://doi.org/10.7289/V51834G7

Urlaub, M., Schmidt-Aursch, M. C., Jokat, W., \& Kaul, N. (2009). Gravity crustal models and heat flow measurements for the Eurasia Basin, Arctic Ocean. Marine Geophysical Researches, 30(4), 277-292. https://doi.org/10.1007/s11001-010-9093-X

Van Wagoner, N. A., Williamson, M. C., Robinson, P. T., \& Gibson, I. L. (1986). First samples of acoustic basement recovered from the Alpha ridge, Arctic ocean: New constraints for the origin of the ridge. Journal of Geodynamics, 6(1-4), 177-196. https://doi.org/10.1016/ 0264-3707(86)90038-4

Vogt, P. R., Taylor, P. T., Kovacs, L. C., \& Johnson, G. L. (1979). Detailed aeromagnetic investigation of the Arctic Basin. Journal of Geophysical Research, 84(B3), 1071-1089. https://doi.org/10.1029/JB084iB03p01071

Von Herzen, R., \& Maxwell, A. E. (1959). The measurement of thermal conductivity of deep-sea sediments by a needle-probe method. Journal of Geophysical Research, 64(10), 1557-1563. https://doi.org/10.1029/JZ064i010p01557

Xiao, W., Zhang, T., Zheng, Y., \& Gao, J. (2013). Heat flow measurements on the Lomonosov Ridge, Arctic Ocean. Acta Oceanologica Sinica, 32(12), 25-30. https://doi.org/10.1007/s13131-013-0384-3 